\title{
Sex Disparities in COVID-19 Severity and Outcome: Are Men Weaker or Women Stronger?
}

\author{
Rosario Pivonello ${ }^{a, b}$ Renata S. Auriemma ${ }^{c}$ Claudia Pivonello ${ }^{c}$ \\ Andrea M. Isidori $^{d}$ Giovanni Corona $^{e}$ Annamaria Colao ${ }^{b, c}$ Robert P. Millar ${ }^{f, g}$ \\ ${ }^{a}$ Dipartimento di Medicina Clinica e Chirurgia, Sezione di Endocrinologia, Unità di Andrologia e Medicina della \\ Riproduzione e della Sessualità Maschile e Femminile (FERTISEXCARES), Università Federico II di Napoli, Naples, \\ Italy; ' UNESCO Chair for Health Education and Sustainable Development, Federico II University, Naples, Italy; \\ 'Dipartimento di Medicina Clinica e Chirurgia, Sezione di Endocrinologia, Università Federico Il di Napoli, Naples, \\ Italy; ${ }^{d}$ Department of Experimental Medicine, "Sapienza" University of Rome, Rome, Italy; ${ }^{e}$ Endocrinology Unit, \\ Medical Department, Maggiore-Bellaria Hospital, Bologna, Italy; ${ }^{f}$ Centre for Neuroendocrinology, Department of \\ Immunology, Faculty of Health Sciences, University of Pretoria, Pretoria, South Africa; ${ }^{9}$ Neurosciences Institute and \\ Institute of Infectious Diseases and Molecular Medicine, University of Cape Town, Cape Town, South Africa
}

\author{
Keywords \\ COVID-19 · Sex disparity · Sex hormones · Inflammaging · \\ Estrogens · Androgens
}

\begin{abstract}
The coronavirus disease 2019 (COVID-19) outbreak, caused by severe acute respiratory syndrome coronavirus 2 (SARSCoV-2), is a global public health issue which has profound effects on most aspects of societal well-being, including physical and mental health. A plethora of studies globally have suggested the existence of a sex disparity in the severity and outcome of COVID-19 patients, mainly due to mechanisms of virus infection, immune response to the virus, development of systemic inflammation, and consequent systemic complications, particularly thromboembolism. Epidemiological data report a sex difference in the severity of COVID-19, with a more favorable course of the disease in women compared to men regardless of age, although the rate of SARS-CoV-2 infection seems to be similar in both sex-
\end{abstract}

es. Sex hormones, including androgens and estrogens, may not only impact virus entry and load, but also shape the clinical manifestations, complications, and ultimately the outcome of the disease. The current review comprehensively summarizes the current literature on sex disparities in susceptibility and outcome of COVID-19 as well as the literature underpinning the pathophysiological and molecular mechanisms, which may provide a rationale to a sex disparity. These mechanisms include sex hormone influence on factors that facilitate virus entry and priming, immune and inflammatory response, as well as coagulation and thrombosis diathesis. Based on present evidence, women appear to be relatively protected from COVID-19 because of a more effective immune response and a less pronounced systemic inflammation, with consequent moderate clinical manifestations of the disease, together with a lesser predisposition to thromboembolism. Conversely, men appear to be particu-

A. Colao and R.P. Millar equally contributed as senior authors. karger@karger.com www.karger.com/nen

Karger ${ }^{\prime}=$
(C) 2020 S. Karger AG, Basel

Via Sergio Pansini 5
IT-80131 Naples (Italy)

rosario.pivonello@unina.it 
larly susceptible to COVID-19 because of a less effective immune response with consequent severe clinical manifestations of the disease, together with a greater predisposition to thromboembolism. In the elderly, generally characterized by the phenomenon of inflammaging, sex disparities in overall mortality following SARS-CoV-2 infection are even more palpable as elderly men appear to be more prone to severe COVID-19 because of a greater predisposition to infections, a weaker immune defense, and an enhanced thrombotic state compared to women. The information revealed from the review highlights potential novel therapeutic approaches employing the administration of hormonal or antihormonal therapy in combination with antiviral drugs in COVID-19 patients.

(c) 2020 S. Karger AG, Basel

\section{Background}

The coronavirus disease 2019 (COVID-19), caused by severe acute respiratory syndrome coronavirus 2 (SARSCoV-2), was first identified in December 2019 in Wuhan, China and rapidly spread globally, reaching pandemic dimensions [1]. At the latest update of October 14, 2020, $>38$ million cases had been reported from 214 countries and territories, resulting in $>1$ million deaths against a background of $>29$ million recoveries (www.worldometers.info/coronavirus). Table 1 shows epidemiological data for COVID-19 from across the world.

The clinical syndrome of COVID-19 typically includes fever and dry cough, less commonly associated with dyspnea and fatigue, muscle and joint pain, headache and dizziness, and gastrointestinal disturbances, together with loss of smell and taste [1]. The wide spectrum of clinical manifestations ranges from a silent (asymptomatic disease) or mild (common cold-type disease) clinical syndrome, in the majority of cases, to a severe disease in a minority of cases, progressing towards acute respiratory distress syndrome, followed by thromboembolism, septic shock, and multiorgan injury, likely in dependence of virus load and host conditions [1]. The dramatic lethality of COVID-19 is related to the relevant capacity of SARS$\mathrm{CoV}-2$ to infect the population and the relevant ability of the infection to induce serious and life-threatening clinical complications in subsets of the population, especially elderly people and subjects with cardiometabolic diseases and/or conditions of immunosuppression [2].

SARS-CoV-2 is a coronavirus belonging to the aggressive beta-CoV type, such as SARS-CoV and MERS-CoV, formed by a single-strand positive RNA covered by an

Sex Disparities in COVID-19 Severity and Outcome envelope that contains the spike proteins responsible for binding to receptors and for fusion with the membrane of host cells $[1,3]$. SARS-CoV-2 binds angiotensin-converting enzyme 2 (ACE2), a regulator of the renin-angiotensin system (RAS) involved in the biotransformation of the vasoconstrictor angiotensin II (AngII) to the vasodilator angiotensin 1-7 (Ang[1-7]), abundantly expressed on the cell surface of human alveolar epithelial cells or pneumocytes, but also present on respiratory tract epithelial cells, intestinal enterocytes, kidney proximal tubule cells, vessel endothelial cells, and cardiomyocytes as well as hematopoietic and immune cells, and used by the virus as an entry receptor into the host cells [1, 4-7]. SARS-CoV-2 uses different protease enzymes, especially transmembrane protease serine 2 (TMPRSS2), a specific protease expressed on the cell surface of human pneumocytes, but also present in intestinal enterocytes, kidney cells, and vessel endothelial cells, as a priming factor through favoring of the internalization of the virus into the host cell, by means of the spike proteins cleavage, which facilitate the fusion of envelope of the virus with the membrane of the host cells and, consequently, virus priming [5]. Importantly, TMPRSS2 and ACE2 are coexpressed not only in the respiratory system, particularly in the lung, but also in the intestine and kidney and the vascular system $[1,4-7]$, which are main targets of SARS$\mathrm{CoV}-2$ and the most frequently damaged organs in COVID-19.

The main conduit of infection is the respiratory system, where ACE2 expression progressively decreases from the nose to the bronchioalveolar tree of the lung [8]. The first relevant host cells for the virus are represented by pneumocytes; inside the pneumocytes, the virus replicates, inducing an increase in virus load, with progeny viruses spreading and infecting surrounding receptive cells $[3,6,9]$. The infected host cells undergo pyroptosis, a dramatic inflammatory form of programmed cell death occurring frequently as a consequence of infection with cytopathic viruses $[6,9]$. During pyroptosis, the activation and assembly of inflammasomes, the typical cytosolic multiprotein complexes responsible for the activation of inflammatory responses, triggers generation and secretion, through the formation of pores in the cell membrane, of proinflammatory cytokines, especially interleukin 1 (IL-1). Ultimately, this phenomenon induces cell destruction with generation and secretion of damageassociated molecular patterns, which together with proinflammatory cytokines are recognized by local cells of the innate immune system, such as alveolar macrophages, triggering the generation and secretion of proinflamma-

Neuroendocrinology 2021;111:1066-1085 DOI: $10.1159 / 000513346$ 
Table 1. Global epidemiological sex-disaggregated mortality data from the Global 5050 dataset (https://globalhealth5050.org/covid19/ sex-disaggregated-data-tracker)

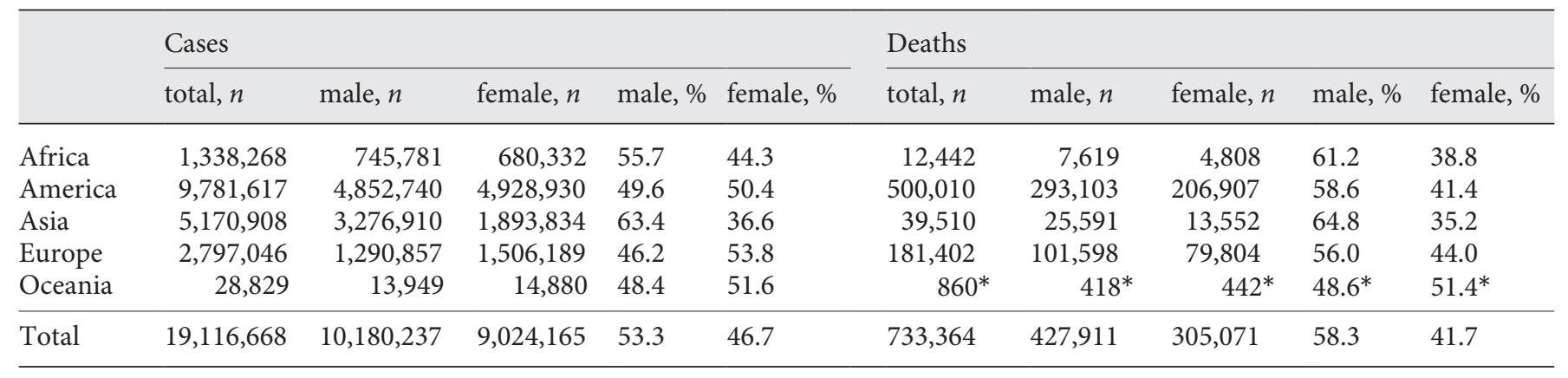

* Data available for Australia only.

tory chemokines and cytokines, especially IL-6. Moreover, cells of the innate immune system, expressing the toll-like receptors (TLRs), including TLR4 and TLR7, able to identify various pathogens, recognize a spike protein and/or the single-strand RNA of SARS-CoV-2 and locally attract additional innate response immune cells, including not only macrophages but also monocytes, dendritic cells, natural killer (NK) cells, and neutrophils, together with cells of the adaptive immune system, especially $\mathrm{T}$ cells, therefore promoting further inflammation, also emphasized by the secretion of $\mathrm{T}$ cell-produced interferon gamma (IFN- $\gamma$ ), and establishing an inflammatory feedback loop $[6,9]$.

The degree of COVID-19 is the result of the interplay between virus virulence and host resistance, with the transition between innate and adaptive immune response still not fully elucidated, playing a crucial role in the clinical progress of the SARS-CoV-2 infection from a mild to a severe disease $[6,9]$. In subjects with healthy immune response, the initial inflammation induced by the innate immune system attracts adaptive immune cells, such as virus-specific $\mathrm{T}$ cells and $\mathrm{B}$ cells, to the site of the infection; T cells, $\mathrm{CD} 4+\mathrm{T}$ ( $\mathrm{T}$ helper) cells, $\mathrm{CD} 8+\mathrm{T}$ (T suppressor) cells, and $\mathrm{T}$ regulatory cells cooperate to eliminate the infected cells before the virus spread, whereas B cells produce virus-specific neutralizing antibodies, which block the virus and permit macrophages to recognize and phagocyte neutralized viruses and death cells, whose elimination is associated with minimal lung damage, resulting in absent or mild clinical syndrome and subsequent recovery $[6,9]$. Conversely, in subjects with preexisting or virus-induced dysfunctional immune response and/or an intense viral load, the immune response is not effective and $\mathrm{T}$ cells and macrophages are not able to in- hibit virus proliferation and to eliminate the infected cells, with B cells eventually producing non-neutralizing antibodies. This condition may enhance virus infection and consequent exaggerated production of cytokines and chemokine, which include not only IL- 1 and IFN- $\gamma$ but also macrophage inflammatory protein 1 , monocyte chemoattractant protein 1, granulocyte colony-stimulating factor, granulocyte/macrophage colony-stimulating factor, tumor necrosis factor (TNF), and various interleukins, such as IL-2, IL-7, IL-8, IL-10, IL-17, IL-18, and especially IL-6, resulting in an excessive inflammatory reaction, or hyperinflammation, characterized by the so-called cytokine storm and responsible for the typical interstitial pneumonia $[6,9]$. Concomitantly, the accumulation of inflammatory cells and cytokines and the virus infection of endothelial cells lead to endothelial cell injury, or endotheliitis, and degradation of extracellular matrix, inducing the loosening of interendothelial junctions and promoting increased vascular permeability and vascular leakage, and determine a typical endotheliopathy [10]. Moreover, neutrophil extracellular traps, structures of nucleotides and proteins expelled by neutrophils to ensnare pathogens, activate platelets that, together with the hypercoagulability, resulting from the inflammatory-induced stimulation of procoagulant factors, such as fibrinogen, tissue factor, factors (F) VIII, FVIIa, FXa, and FIIa and von Willebrand factor, and mainly from the inhibition of anticoagulant factors, such as tissue factor pathway inhibitor, antithrombin III and activated C protein, lead to the development of microvascular thrombosis [11]. The status of hyperinflammation and hypercoagulability act together in inducing thromboembolism in the lungs, thus leading to respiratory failure [12]. Notably, the hyperinflammation, with recruitment of immune 


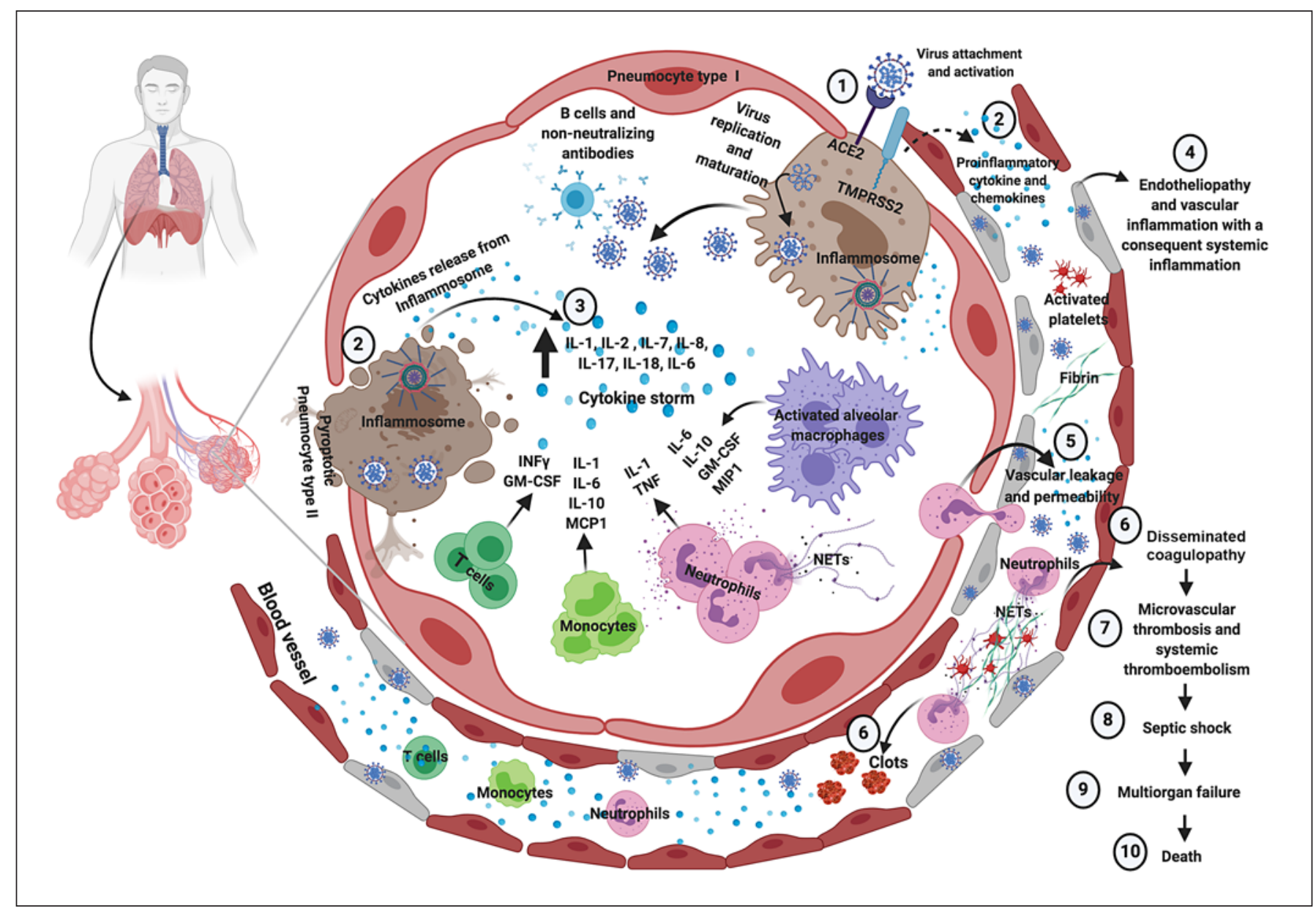

Fig. 1. Immune, inflammatory, and thrombotic response to SARSCoV-2 infection in case of severe COVID-19. SARS-CoV-2 enters into cells expressing the surface ACE2 receptors and TMPRSS2 (1). The replication and release of SARS-CoV-2 cause pyroptosis of host cells and release of proinflammatory cytokines by inflammasomes (mainly IL-1, IL-8, and IL-18) and cell debris that activate alveolar macrophages, which in turn further release proinflammatory cytokines (mainly IL-10, GM-CSF, and MIP1) and chemokines (2). These proteins attract other innate and adaptive immune cells in the lungs, damaging the lung infrastructure and with the addition of increasing release of IFN- $\gamma$ by T cell promoting a proinflammatory feedback loop and cytokine storm (3). Moreover, production of non-neutralizing antibodies by B cells may enhance SARS-CoV-2 infection, further exacerbating organ damage. Concomitantly, the damage of endothelial tissue directly caused by SARS-CoV-2 entry and the local inflammation induce endotheliopathy characterized by injured endothelial tissue (4) with consequent vascular leaking (5). Neutrophil extracellular traps induce the aggregation of platelets and fibrin deposition, leading to blood clots formation and promoting disseminated coagulopathy (6). This mechanism finally results in microvascular thrombosis and systemic thromboembolism (7). As a consequence, septic shock and multiorgan failure may develop and represent potential major death determinants in COVID-19. Figure created with www.biorender.com. ACE2, angiotensin-converting enzyme 2; COVID-19, coronavirus disease 2019; GM-CSF, granulocyte-macrophage colony-stimulating factor; IFN- $\gamma$, interferon gamma; IL, interleukin; MCP1, monocyte chemoattractant protein 1 ; MIP1, macrophage inflammatory protein 1 ; NETs, neutrophil extracellular traps; SARS-CoV-2, severe acute respiratory syndrome coronavirus 2; TMPRSS2, transmembrane protease serine 2; TNF, tumor necrosis factor. cells from the blood to the lungs and infiltration of lymphocytes to the airways, and the consequent hypercoagulability may explain the main laboratory findings of the COVID-19-related interstitial pneumonia, biochemically characterized by lymphopenia, increase in inflammatory markers (erythrocyte sedimentation rate, C-reactive protein, ferritin), alteration of coagulation parameters (prolonged thrombin and prothrombin time, prolonged international normalized ratio, thrombocytopenia, increase in fibrinogen and D-dimer), together with a dramatic in- 
Table 2. Sex disparities of mortality data in COVID-19 available from literature

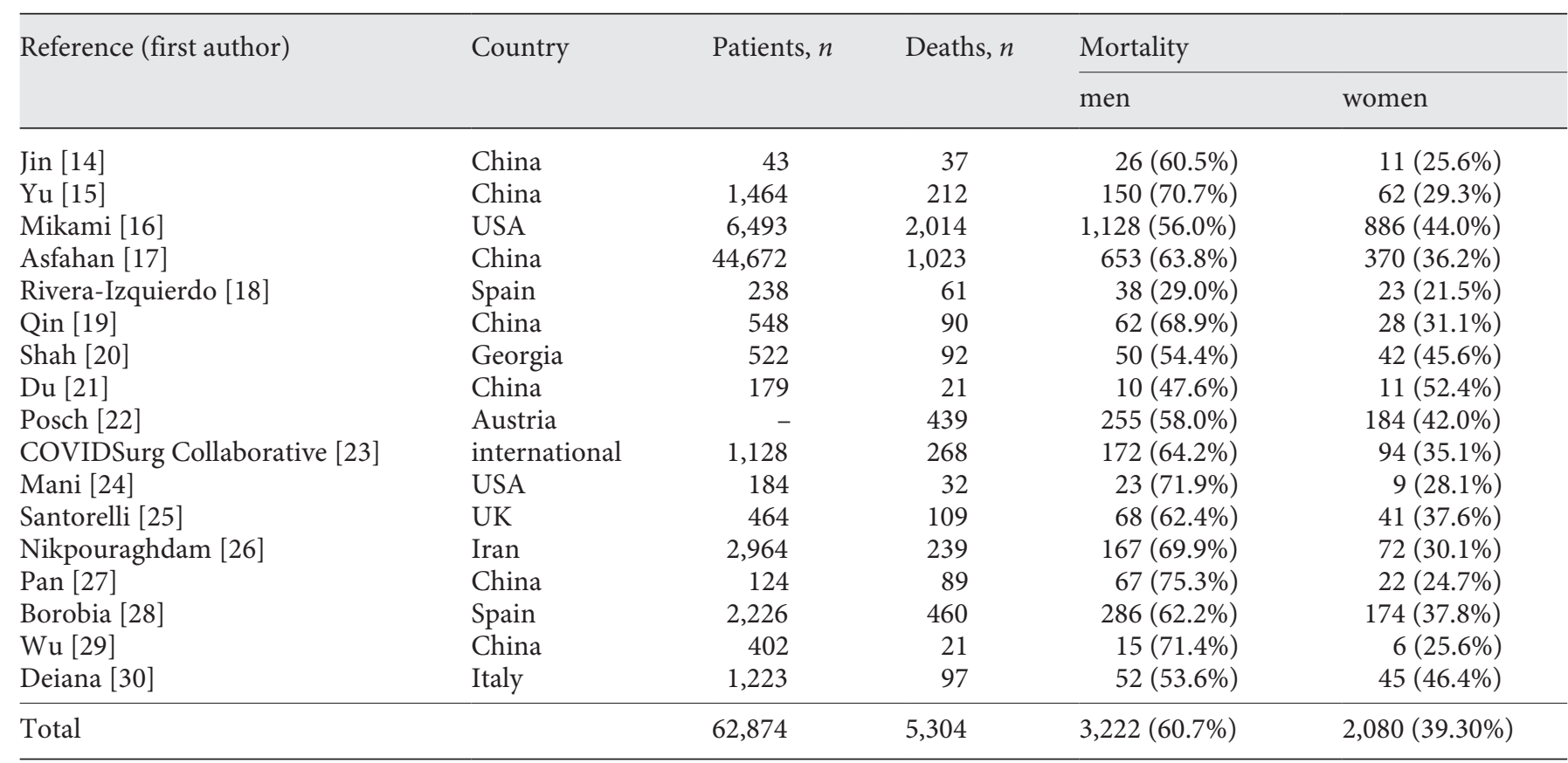

COVID-19, coronavirus disease 2019.

crease in cytokines, such as TNF and, especially, IL-1 and IL-6 $[1,2]$. The hyperinflammation, with the cytokine storm, because of endotheliopathy and vascular permeability, circulates to different organs, with resulting systemic inflammation, whereas hypercoagulability leads to disseminated coagulopathy, resulting in diffuse thrombosis. The consequent cardiovascular collapse and reduction in peripheral perfusion lead to septic shock and multiorgan injury, with consequent liver and kidney failure that is likely the major cause of death in COVID-19 [9, 12].

Figure 1 shows the dysfunctional immune response and the exaggerated inflammatory response to SARSCoV-2 infection in case of severe COVID-19, which promotes systemic inflammation, endotheliopathy, disseminated coagulopathy, and thromboembolism, leading to septic shock, multiorgan injury, and eventual death.

\section{Sex Disparities in the Severity and Outcome of COVID-19}

Although global epidemiological data suggest a similar prevalence in virus infection between men and women, a clear sex-related difference in the severity of the disease, with a more favorable outcome in women compared to men, has been described [13-30]. Indeed, according to the last update of the global situation on October 14, 2020 the overall prevalence of infection in men and women was 53.3 and $46.7 \%$, respectively, whereas the prevalence of death in men and women was 58.3 and $41.7 \%$, respectively. In Italy, which was among the first countries, after China, to be involved in the world and one of the countries with the highest contagion and lethality in Europe, the National Institute of Health (NIH) confirmed a difference in mortality between men and women. At the update on March 30, 2020, corresponding to the week following the first Italian epidemiological peak of the infection, the NIH reported in the entire Italian population an infection rate slightly higher in men $(52,206,55.7 \%)$ than in women $(41,549,44.3 \%)$, but a lethality rate in men $(6,930,13.3 \%)$ which almost doubled that recorded in women $(3,083,7.4 \%)$, with a clearly higher relative prevalence of death in men (69.1\%) than in women (30.8\%). This finding was confirmed at all age groups and is strengthened by the evidence of a median age of deceased patients lower in men ( 79 years) than in women ( 85 years) (www.epicentro.iss.it/coronavirus). Noteworthy, during the first phases of pandemic, the infection rate was calculated predominantly on the symptomatic population, 
which was generally tested for the presence of the virus. Conversely, during the second phase of the pandemic, a wider population was tested for the presence of the virus, including predominantly asymptomatic subjects who were in contact with symptomatic and/or positive subjects in a population prevention strategy, with an expected change of the infection rate in men and women. Interestingly, a sex-related difference was partially confirmed at the latest update on October 14, 2020 when the NIH reported in the entire Italian population a slightly lower infection rate in men $(173,180,48.3 \%)$ than in women $(185,300,51.7 \%)$, but a lethality rate in men $(20,759,12 \%)$ persistently higher, although to lesser extent, than in women $(15,474,8.4 \%)$, with a higher relative prevalence of death in men $(57.3 \%)$ than in women $(42.7 \%)$, nevertheless testifying the persistence of the sex-related difference in disease severity and outcome. This finding was confirmed in all age groups including the elderly, where the lethality rate was still higher in men compared to women. The progressive reduction in the sex-related difference in lethality might reflect a more timely and accurate diagnosis, a wider search for the presence of the virus in symptomatic and asymptomatic subjects, and a more effective treatment, consequence of the increasing knowledge of the infection mechanisms and body reactions, also considering the typical trend of the Italian population, where the elderly population (especially people aged $>80$ years) is composed of more women than men.

A similar epidemiological disparity between sexes was previously reported in patients with SARS and MERS, with the mortality rate being higher in elderly men, especially those with critical illness [31].

Table 1 shows the overall prevalence of infections and deaths in men and women worldwide. Table 2 shows sex disparities of mortality data in COVID-19 available from literature.

\section{Hypotheses Underlying Sex Disparities in COVID-19 Outcome}

Several hypotheses have been postulated to explain the greater severity and the less favorable outcome of COVID-19 in men compared to women. Differences in cultural and social behaviors in men and women have been claimed $[32,33]$, together with the presence of comorbidities, such as cardiovascular and respiratory diseases, as well as smoking habits and alcohol intake, which are generally more prevalent in men compared to women [33]. Furthermore, the disparities between sexes has been

Sex Disparities in COVID-19 Severity and Outcome also attributed to the evidence that men adhere to hygiene practices, including simple handwashing behavior, less rigorously and assiduously than women [33, 34], with consequent easier infection and burden of the disease in men compared to women.

Besides these considerations, an increasing body of evidence has indicated that the sex-related difference in the severity and outcome in COVID-19 patients is mainly ascribable to mechanisms of virus infection, immune response to the virus, development of hyperinflammation and hypercoagulability, and/or systemic inflammation and thromboembolism.

The current review describes the present evidence focusing on data derived from human studies and including animal studies in sections with scarce, conflicting, or absent human studies. However, some of the investigations reporting on these mechanisms are not always robustly evidence-based, permitting exclusively an iconoclastic but balanced assessment of current available information on the issue.

\section{Sex Disparities in the Mechanisms of Virus Infection}

Similarly to SARS-CoV, but differently from MERS$\mathrm{CoV}$, SARS-CoV-2 uses the cell surface enzyme ACE2 and the protease TMPRSS2 that provide virus cell entry and priming. Different genetic and endocrine mechanisms, including sex hormone actions, might influence the mechanisms of SARS-CoV-2 infection.

Genetic mechanisms seem to regulate ACE2 and TMPRSS2 expression in humans differently in men and women. ACE2 appears to be differently expressed in men and women supposedly due to the gene localization on $\mathrm{X}$ chromosome, but the differential expression seems to occur in a tissue-specific manner. Surprisingly, although $\mathrm{ACE} 2$ is an $\mathrm{X}$-linked gene escaping from $\mathrm{X}$ inactivation, suggesting a greater generalized expression in women compared to men, data from postmortem donors displayed a significant male-biased ACE2 expression in the majority of tissues, including lung, gastrointestinal system, and blood vessels, and a female-biased ACE2 expression in a minority of tissues, including subcutaneous adipose tissue, cardiac left ventricle, and pancreas [35]. However, ACE2 expression in bronchial epithelial cells has been supposed to be higher in women than in men, since the ACE2 gene has been demonstrated to be epigenetically regulated through DNA methylation, with evidence of hypomethylation in women compared to men [36]. Interestingly, ACE2 was expressed in the male reproductive system, especially in the testis, and particularly in spermatogonia as well as Leydig and Sertoli cells 
[37], and in the female reproductive system, especially in the ovary [38], although the impact of SARS-CoV-2 infection and COVID-19 on gonadal function is not fully investigated [39]. In contrast to ACE2, TMPRSS2 is apparently not associated with a significant sex-related differential expression in humans, likely because the gene is not localized on sex chromosomes. Despite bioinformatic reports of a slightly increased TMPRSS2 level in bronchial epithelial cells in men compared to women, a nonsignificant sex-biased TMPRSS2 expression has been demonstrated in the lung [40]. Noteworthy, the presence of different single nucleotide polymorphisms (SNPs) in the TMPRSS2 gene leads to the formation of two specific haplotypes; one of these haplotypes, characterized by the presence of three specific SNPs and more frequently expressed in Italian than East Asian populations, is predicted to be associated with upregulation of TMPRSS2 expression and has been found to be also associated with increased susceptibility to H7N9 influenza A virus infection, whose incidence is double in men compared to women; this evidence might also explain the high susceptibility to SARS-CoV-2 infection and lethality of COVID-19 in Italian men [40]. Interestingly, TMPRSS2 is expressed in the male reproductive system, predominantly in the prostate, seminal vesicles, and epididymis but not in the testes [41], and seems not to be expressed in the female reproductive system [42], although the impact of SARS-CoV-2 infection and COVID-19 on gonadal function is not fully investigated [39].

Endocrine mechanisms, including the action of sex hormones, seem to regulate ACE2 and TMPRSS2 expression and/or function in a species- and tissue-specific manner differently in males and females. Noteworthy, sex hormones have been found to modulate not only ACE2 expression, but also ACE2 activity, probably through posttranscriptional or posttranslational mechanisms, although with conflicting results between animals and humans. In rodents, where renal ACE2 expression and activity are higher in males than females, gonadectomy, characterized by a suppression of sex hormone production, increased renal ACE2 activity in females but not in males, whereas estradiol treatment reduced renal ACE2 activity in both gonadectomized males and females [43], suggesting a negative role of estrogens in modulating ACE2 activity and, consequently, cardiovascular homeostasis in animal models. Nevertheless, testosterone treatment was found to modulate the RAS pathway, in particular to upregulate the classical pressor pathway (ACE/ AngII/AT1R axis), by increasing renal and hepatic angiotensinogen expression as well as renal renin expression and activity and AT1R expression [44, 45], and downregulate the depressor pathway (ACE2/Ang(1-7)/AT2R axis), by decreasing myocardial ACE2 activity and aortic AT2R expression in models of gonadectomized male and/or gonadectomized and non-gonadectomized female rodents $[46,47]$. Notably, in non-gonadectomized male mice, treatment with the androgen receptor antagonist enzalutamide has been shown to decrease lung ACE2 expression, which became similar to the expression registered in female mice [48]. Moreover, the sex-determining region Y (SRY) gene, located on the Y chromosome, seems to be responsible for the upregulation of the pressor pathway, particularly angiotensinogen, renin, and $\mathrm{ACE}$, and the downregulation of depressor pathway, particularly ACE2, expression in experimental models of transfected Chinese hamster ovary $(\mathrm{CHO}-\mathrm{K} 1)$ cell line [49]. These controversial data on different tissues do not clarify whether androgens exert a potential positive effect in modulating ACE2 activity and the RAS pathway and, consequently, cardiovascular homeostasis in animal models. Conversely, in humans, in an experimental model of cardiac atrial tissue derived from elderly men, estradiol treatment induced a shift from ACE to ACE2 expression and consequently from the classical pressor ACE/ AngII/AT1R pathway to the alternative depressor ACE2/ Ang(1-7)/AT2R pathway of the RAS pathway [50, 51]. Moreover, in transgender women, estradiol treatment reduced blood pressure by stimulation of ACE 2 activity and increase in Ang(1-7)/AngII balance [52]. This evidence suggested that estrogens stimulate ACE2 expression and activity, with a positive final effect on cardiovascular homeostasis in humans. Sex hormones, particularly androgens and to a smaller extent estrogens, have been also found to modulate TMPRSS2 expression, although with conflicting results between animals and humans. In rodents, lung TMPRSS2 expression is unaffected by the use of the androgen receptor antagonist enzalutamide in males, suggesting the absence of androgen stimulation of TMPRSS2 expression [48]. Conversely, in humans, testosterone stimulates TMPRSS2 expression in human prostate cancer cells [53], whereas estradiol stimulates and inhibits TMPRSS2 expression in human prostate and breast cancer cells, respectively $[54,55]$, in an experimental setting, suggesting a major role of androgens on enhancing TMPRSS2 expression. Interestingly, in humans, a second specific haplotype, including TMPRSS2 variants, and characterized by the expression of at least seven SNPs, has been denominated European haplotype because it is relatively frequent in the European, including the Italian, and totally absent in the East Asian, popula- 


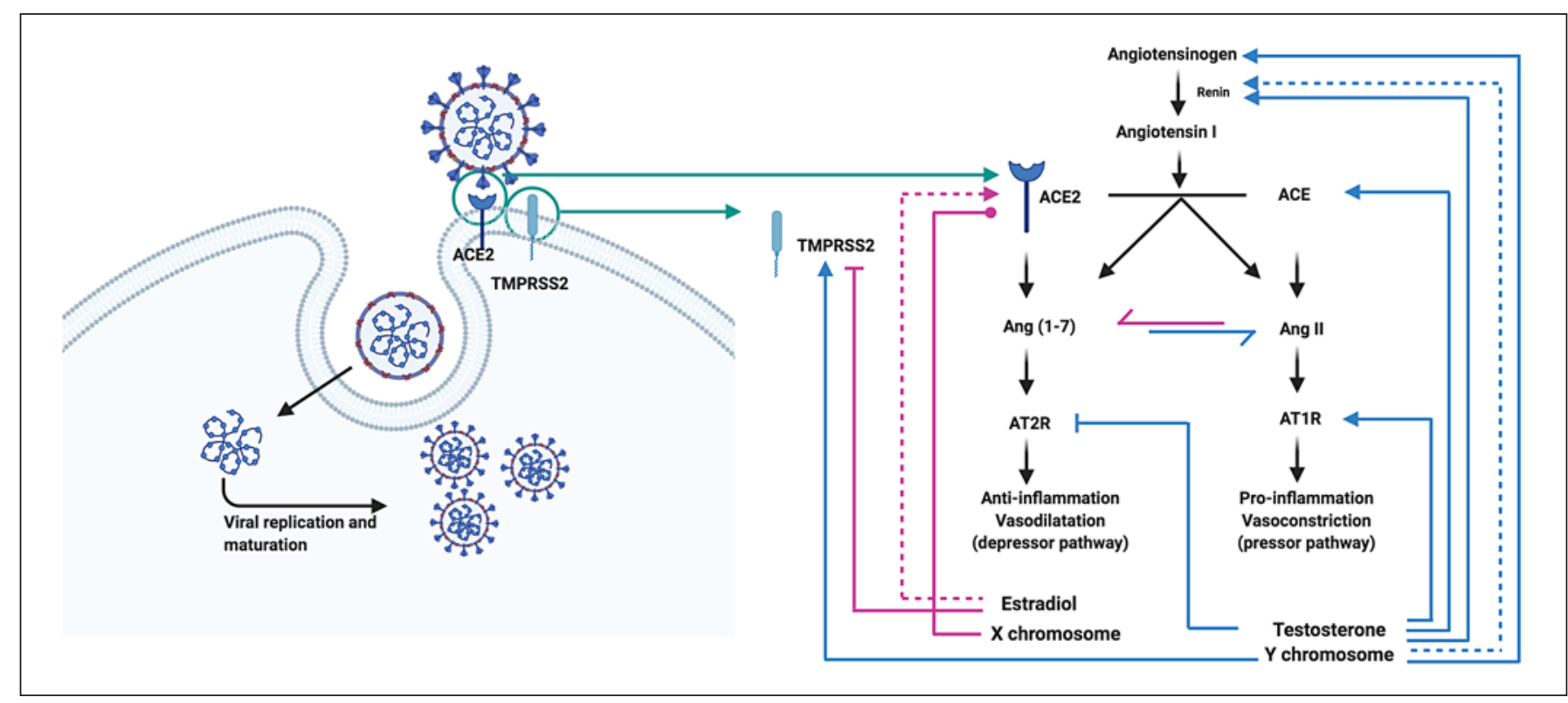

Fig. 2. Sex chromosome and sex hormone regulation of TMPRSS2 and ACE2 expression and activity, and implications in RAS function. ACE2 and TMPRSS2 are stechiometrically contiguous and mediate SARS-CoV-2 cell fusion and entry. ACE2, being an Xlinked gene, should be supposed to be more expressed in female tissue (pink line with dot). However, despite being an X-linked gene escaping from $\mathrm{X}$ inactivation, ACE2 displays a male-biased expression in several tissues. Subsequently to membrane fusion and virus entry into the host cell, SARS-CoV-2 infection leads to downregulation of ACE2. As a result, the ACE2/Ang(1-7)/AT2R axis is markedly attenuated, with amplification of the pressor ACE/AngII/AT1R axis. Sex chromosome and sex hormones contribute to RAS regulation. In males, sex hormones and genes in sex chromosomes contribute by differentially modulating the RAS. Specifically, testosterone upregulates the expression of angiotensinogen and AT1R (blue line with arrow), reduces the expression of AT2R (blue line with inhibitor), and concomitantly inhibits re- nin activity (blue dashed line with arrow). Moreover, SRY genes upregulate angiotensinogen, renin, and ACE expression (blue line with arrow) and downregulate ACE2 expression (blue line with inhibitor). These effects upregulate the classical constrictor and proinflammatory pathway ACE/AngII/AT1R axis. Moreover, testosterone positively regulates TMPRSS2 expression (blue line with arrow). In contrast, estradiol changes the balance towards depressor and anti-inflammatory ACE2/Ang(1-7)/AT2R axis increasing ACE2 activity (pink dashed line with arrow). Moreover, estradiol negatively regulates TMPRSS2 expression (pink line with arrow). Figure created with www.biorender.com. ACE, angiotensinconverting enzyme; ACE2, angiotensin-converting enzyme 2; Ang(1-7), angiotensin 1-7; AngII, angiotensin II; RAS, renin-angiotensin system; SARS-CoV-2, severe acute respiratory syndrome coronavirus 2; SRY, sex-determining region Y; TMPRSS2, transmembrane protease serine 2 .

sociated with increased susceptibility to viral infection, might theoretically increase susceptibility to SARSCoV-2 infection and contribute to a higher virus spread as well as development of more severe disease with worse outcome. Conversely, in women, the reduced ACE2 expression in the lung and the estrogen inhibition of TMPRSS2 expression might theoretically reduce the susceptibility to SARS-CoV-2 infection and contribute to a lower virus spread as well as development of less severe disease with better outcome. Interestingly, the estrogendependent stimulation of ACE2 activity might play a crucial role in cardiovascular protection and confer to women a more effective defense compared to men against deterioration of the clinical course of the disease, at least during the reproductive age. Notably, this difference in 
the mechanisms of virus infection seems to have an impact on disease severity and outcome but apparently not on the prevalence of infection, since the rate of SARSCoV-2 infection seems to be similar in men and women, particularly slightly higher initially and recently slightly lower in men than in women, contrary to the severity and outcome of the disease, which was always clearly worse in men than in women.

\section{Sex Disparities in Immune and Inflammatory}

Response

Similarly to SARS and MERS, it is generally established that severe COVID-19 is characterized by a dramatic inflammatory state initially localized in the lung, due to the massive release of proinflammatory cytokines produced by virus-infected cells, which attracts towards the site of infection innate immune cells, which are also infected by the virus $[3,6,9]$. In case of preexisting or virus-induced dysfunctional immune response, the enhanced release of proinflammatory cytokines and the recruitment of the immune cells from the blood to the site of infection might damage the lung and establish a proinflammatory feedback loop, determining vascular permeability and a cytokine storm, which in turn may diffuse through the circulation into the various organs, promoting multiorgan injury and leading to the development of systemic illness [3, 6 , 9]. Nevertheless, a very recent study proposed an intriguing theory, suggesting that SARS-CoV-2 infection might directly induce an immunological collapse secondary to severe immunosuppression, with reduction of CD4+ T cells, CD8+ T cells, B cells, and NK cells, leading to a profound defect in host immunity and consequent failure to control unrestrained virus replication and dissemination with direct host cytotoxicity, rather than to cytokine storm-induced multiorgan failure [56].

Different genetic and endocrine mechanisms, including sex hormone actions, might influence the mechanisms of immune and inflammatory response to COVID-19.

Genetic mechanisms seem to regulate susceptibility to infections and directly impact immune response between sexes, with distinctions in innate and adaptive immune responses that remain constant from birth to old age [57]. Sexual dimorphism in animal and humans contributes to a stronger immune response in females compared with males. The sex-related difference in immune response is mainly due to the evidence that a relevant number of genes involved in the positive regulation of innate and adaptive immune response is located on sex chromosomes, especially on the X chromosome. Indeed, males have only one X chromosome, a condition that from an evolutionary point of view represents a disadvantage, as every newly arisen recessive and deleterious mutation on the X-linked genes, including the immune-related genes, results in the functional loss in the entire cohort of cells and is manifested phenotypically. Conversely, females are generally protected by this phenomenon because one of the $\mathrm{X}$ chromosomes is randomly inactivated, resulting in cell mosaicism where only half of cells result in the functional loss following the eventual deleterious mutation, including functional loss of immune function [58]. Moreover, cell mosaicism also confers an additive immunological advantage to females compared to males in case of $\mathrm{X}$-linked genes escaping inactivation; indeed, the $\mathrm{X}$ linked immune-related genes extensively and generally positively involved in innate and adaptive immune response might result in a relatively increased level of functional immune factors, likely protecting females more than males from infections, including virus infections, or to mitigate the clinical manifestation of the infectious disease in females more than in males, with a different impact on prognosis [58]. In addition, genetic variations among genes on the $\mathrm{Y}$ chromosome are suggested to negatively influence immune response, thus increasing susceptibility to infections in males compared to females [59].

Differences in susceptibility to respiratory viral infectious diseases between males and females have been shown in rodent models. Male mice infected with SARSCoV-MA15, reproducing a clinical syndrome similar to SARS, are more susceptible to disease than females, and the degree of sex bias increases with advancing age; the enhanced susceptibility of male mice was associated with elevated virus titers, neutrophil infiltration, and proinflammatory cytokine (IL-1, IL-6, and TNF) levels in the lungs, suggesting a worse innate and adaptive immune response in males than in females, probably related to the different expression and function of immune-related genes on the $\mathrm{X}$ chromosome [31]. In male mouse consomic strains, genetic variations in the $\mathrm{Y}$ chromosome predispose males to H1N1 influenza A virus infection, confirming the potential negative role of the $\mathrm{Y}$ chromosome in the immune response and in the susceptibility to specific viral infections [60]. These studies are consistent with the findings of an increased risk for a number of infectious diseases due to genetic background and of a more severe clinical manifestation due to a more profound inflammatory response in men compared to women. Men are more likely to develop severe respiratory inflammatory syndrome as a consequence of lung neutrophil infil- 
Table 3. Sex difference in innate and adaptive immune response based on data from humans and rodents

\begin{tabular}{|c|c|c|}
\hline Immune cells & Characteristic & Sex difference \\
\hline \multicolumn{3}{|c|}{ Innate immune system } \\
\hline Dendritic cells & IFN activity & higher in females \\
\hline Macrophages & $\begin{array}{l}\text { activation and phagocytic ability } \\
\text { proinflammatory cytokine production }\end{array}$ & $\begin{array}{l}\text { higher in females } \\
\text { higher in males }\end{array}$ \\
\hline Neutrophils & phagocytic ability & higher in females \\
\hline NK cells & NK cell number & higher in males \\
\hline \multicolumn{3}{|c|}{ Adaptive immune system } \\
\hline T cells & $\begin{array}{l}\text { CD4+ T cell number } \\
\text { CD8+ T cell number } \\
\text { CD4+/CD8+ T cell ratio } \\
\text { Th1 and Th2 cells }\end{array}$ & $\begin{array}{l}\text { higher in females } \\
\text { higher in males } \\
\text { higher in females } \\
\text { Th2 cell bias in females } \\
\text { Th1 cell bias in males }\end{array}$ \\
\hline B cells & B cell number and activity & higher in females \\
\hline
\end{tabular}

IFN, interferon; NK, natural killer; Th1, type $1 \mathrm{~T}$ helper; Th2, type $2 \mathrm{~T}$ helper.

tration and exaggerated production of proinflammatory cytokines, whereas females generally have a more favorable outcome, particularly when virulent pathogens are provided of a relevant inflammatory potential [61]. This evidence is also likely to apply to different viral infections, including coronavirus and, particularly, SARS-CoV-2 infection and consequent COVID-19.

Studies on rodents demonstrated a difference in innate and adaptive immune response between males and females, with females possessing a greater activity of innate immune cells, including macrophages, dendritic cells and neutrophils, and a greater number and/or activity of adaptive immune cells, belonging either to humoral or cell-mediated responses, specifically with an increase in B cell number and activity, as well as type $1 \mathrm{~T}$ helper (Th1) and type $2 \mathrm{~T}$ helper (Th2) responses, compared to males, with contradictory difference in regulatory $\mathrm{T}$ cell response [57].

In humans, men and women display differences in the innate immune response, with men possessing an increased number of NK cells and an enhanced ability of macrophages to produce proinflammatory cytokines, and with women displaying an enhanced ability to activate dendritic cells with consequent increase of IFN production, and macrophages and neutrophils with consequent increase in phagocytotic activity [57]. Notably, TLR4, whose genomic localization is on chromosome 3, is an extracellular receptor-binding lipopolysaccharide which influences cytokine production and displays, for unclassified reasons, higher expression on immune cells derived from men than those derived from women [57]. Conversely, TLR7, whose genomic localization is on the $\mathrm{X}$ chromosome, is an intracellular receptor that binds single-stranded nucleic acids and, due to escape from $\mathrm{X}$ chromosome inactivation, results in greater expression in immune cells derived from women than in those derived from men [62]. Similarly, men and women also display differences in adaptive immune response, with men possessing an increase in CD8+ T cell number and a Th1 bias, and women possessing an increase in $\mathrm{CD} 4+\mathrm{T}$ cell number with a Th2 bias, together with an increase in $\mathrm{T}$ cell activity in terms of proliferation, activation, and cytotoxicity, and an increase in B cell number and activity, leading to an increased ability to produce antibodies [57]. Table 3 shows the sex difference in innate and adaptive immune response based on data from humans and rodents.

Endocrine mechanisms, including sex hormone actions, seem to influence immunological mechanisms, including inflammatory response, either in the innate or adaptive immune response, differently in men and women throughout the course of life, as demonstrated by studies conducted on both rodents and humans [57]. Studies on rodents demonstrated that androgens reduce macrophage TLR4 expression in gonadectomized male mice [57]. Moreover, studies in rodents and humans revealed that androgens induce immunosuppressive and anti-in- 
Table 4. Impact of sex hormones on innate and adaptive immune responses based on data from humans and rodents

\begin{tabular}{|c|c|c|}
\hline Males (androgens) & \multicolumn{2}{|c|}{ Females (estrogens) } \\
\hline$\downarrow$ NK cell number & \multicolumn{2}{|c|}{$\uparrow \mathrm{NK}$ cell number } \\
\hline$\downarrow$ IFN- $\gamma$ & \multicolumn{2}{|l|}{$\uparrow \mathrm{IFN}-\gamma$} \\
\hline$\downarrow \mathrm{IL}-4$ & \multicolumn{2}{|l|}{$\uparrow \mathrm{IL}-4$} \\
\hline$\downarrow \mathrm{IL}-5$ & \multicolumn{2}{|l|}{$\uparrow \mathrm{IL}-5$} \\
\hline \multirow[t]{2}{*}{$\uparrow \mathrm{IL}-10$} & \multicolumn{2}{|l|}{$\uparrow \mathrm{IL}-10$} \\
\hline & Low-E & High-E \\
\hline$\uparrow \mathrm{IL}-1$ & $\uparrow \mathrm{IL}-1$ & $\downarrow$ IL-1 \\
\hline$\uparrow \mathrm{IL}-6$ & $\uparrow \mathrm{IL}-6$ & $\downarrow$ IL-6 \\
\hline$\downarrow \mathrm{TNF}$ & $\uparrow \mathrm{TNF}$ & $\downarrow \mathrm{TNF}$ \\
\hline$\downarrow$ Th1 and Th2 activity & $\uparrow$ Th1 activity & $\uparrow$ Th2 activity \\
\hline$\downarrow \mathrm{B}$ cell number and activity & \multicolumn{2}{|l|}{$\uparrow \mathrm{B}$ cell activity } \\
\hline$\downarrow$ CD8+ number and activity & \multicolumn{2}{|l|}{$\uparrow \mathrm{CD} 8+$ activity } \\
\hline$\downarrow$ Antibody response & \multicolumn{2}{|c|}{$\uparrow$ Antibody response } \\
\hline
\end{tabular}

High-E, high estrogens (luteal phase of reproductive cycle and pregnancy); IFN- $\gamma$, interferon gamma; IL, interleukin; Low-E, low estrogens (follicular phase of reproductive cycle and menopause); NK, natural killer; Th1, type 1 T helper; Th2, type 2 T helper; TNF, tumor necrosis factor.

flammatory actions by reducing NK and macrophage activity, CD8+ T cell number and activity, Th1 and Th2 cell activity, and B cell number and activity [57]. On the other hand, studies on rodents demonstrated that estrogens induce macrophage TLR4 expression and enhance dendritic cell TLR7 signaling in gonadectomized female mice [57]. Interestingly, administration of high doses of estradiol in mice exposed to SARS-CoV protects against the damage of inflammatory response in the lung through recruitment of monocytes, macrophages, and neutrophils that enhance the CD8+ T cell response [31]. Moreover, studies on humans demonstrated that estrogen administration increases the activation of TLR7 signaling in dendritic cells of postmenopausal women [57]. Notably, estrogens, whose levels increase in women during the follicular phase and decrease during the luteal phase of the menstrual cycle and are very high in pregnancy and very low in menopause, differentially modulate the innate and adaptive immune system in a concentration-dependent fashion. Indeed, low concentrations of estrogens are proinflammatory, inducing IL-1, IL-6, and TNF production and inducing the activity of Th1 cells, whereas high concentrations of estrogens are anti-inflammatory, reducing
IL-1, IL-6, and TNF production and inducing Th2 activity [57]. Therefore, the totality of this evidence suggests that the susceptibility and response to SARS-CoV-2 in COVID-19 may vary depending on sex, and in women throughout the course of life during the different phases of the reproductive cycle. Table 4 shows the impact of sex hormones on innate and adaptive immune responses based on data from humans and rodents.

Additionally, sex hormones interact with the hypothalamus-pituitary-adrenal (HPA) axis, particularly with the systemic effectors glucocorticoids (GCs), and cooperate in the regulation of the immune and inflammatory response. GCs have an immunomodulatory action with predominant immunosuppression, specifically suppressive effects on innate and adaptive immune cells and on inflammatory reaction [63]. Moreover, GCs inhibit the hypothalamus-pituitary-gonadal axis in both sexes, blocking the secretion of testosterone from the testes and of estradiol from the ovaries [64]. In turn, estradiol has a direct stimulatory effect, whereas testosterone has a mild suppressive effect on the HPA axis [64]. These data contribute in explaining the generally superior ability of women to be protected from infections and to respond to infectious diseases.

Taken together, these findings suggest that men and women differ in their genetic predisposition to infectious diseases. In men the single $\mathrm{X}$ chromosome and cluster of gene polymorphisms located on the Y chromosome confer immunological disadvantage and, consequently, a greater frailty against infections. Moreover, the androgen-mediated immunosuppressive and proinflammatory effects, leading to a less effective innate and adaptive immune response, together with the inhibitory effect of androgens on the HPA axis contribute to a more severe disease with worse outcome. Conversely, in women the double X chromosomes, with the possibility of escape from $\mathrm{X}$-linked gene inactivation, and the lack of a Y chromosome confer immunological advantage and, consequently, a greater protection from infections. Moreover, the estrogen-mediated immunostimulatory and anti-inflammatory effects, leading to a more effective innate and adaptive immune response, together with the stimulatory effect of the HPA axis contribute to a less severe disease with better outcome, especially during the reproductive age.

\section{Sex Disparities in Coagulopathy and Thrombosis}

Similarly to SARS and MERS, it is generally established that severe COVID-19 is characterized, concomitantly to dysfunctional immune response and systemic inflamma- 
tion, by disseminated coagulopathy and thromboembolism, which is a major contributor of death [65]. The hemostatic changes represented by the increase in procoagulant and decrease in anticoagulant pathways appear to be supported by a direct virus-induced damage, systemic inflammation, and endotheliopathy, together with liver dysfunction [12]. Presently, the coagulopathy associated with COVID-19 is denominated thromboinflammation, since it appears to result most likely from the systemic inflammation secondary to virus infection, favored by endotheliopathy and complicated by prolonged stasis, rather than from an intrinsic thrombotic effect of the virus [12, 66-68]. Indeed, the dramatic increase in IL-6, the main marker of hyperinflammation, is correlated with fibrinogen, a marker of hypercoagulability, therefore confirming the strong correlation between systemic inflammation and disseminated coagulopathy in COVID-19 [69]. Additionally, the virus infection of endothelial cells induces inflammatory infiltration and consequent cell apoptosis, which generate the peculiar endotheliopathy, with consequent platelet activation and thrombus formation with development not only of microvascular but also macrovascular thrombosis $[12,66,68]$. Microvascular thrombosis was directly demonstrated by recent evidence at autopsy in patients who had died from COVID-19, demonstrating widespread microangiopathy and thrombosis into the lung as well as into different organs and districts of the body $[7,70]$, whereas macrovascular thrombosis has been demonstrated by the occurrence of ischemic stroke and/or acute coronary syndrome and myocardial infarction in patients with COVID-19 [66, 71, 72].

Different genetic and endocrine mechanisms, including sex hormone actions, might influence the mechanisms of coagulopathy and thrombosis in COVID-19.

Genetic mechanisms seem to regulate hemostasis in humans without difference in men and women. Indeed, some genetic variants, such as factor $\mathrm{V}$ Leiden, prothrombin G20210A, and blood group non-0 are known to induce a 2 - to 5 -fold increase in the risk of thrombosis, but none of the genes coding for these factors are on sex chromosomes, and no difference between men and women has been found in the relative risk of thrombosis related to genetic risk factors [73].

Endocrine mechanisms, including sex hormone actions, seem to regulate hemostasis differently in males and females. Indeed, sex hormones directly act on platelet response and coagulation cascade [74]. Evidence emerging from rodents demonstrated a distinct effect of androgens and estrogens on hemostasis. Indeed, treatment with estrogens reduced platelet aggregability in female rats

Sex Disparities in COVID-19 Severity and Outcome
[75] and thrombus formation in female and male rats [76]. In both male and female rats, treatment with testosterone markedly increased mortality and thrombus size, which was doubled in males compared to females at baseline, whereas treatment with estradiol decreased mortality in both sexes and thrombus size in male but not in female rats, with treatment with the androgen receptor antagonist flutamide antagonizing testosterone-increased mortality rate in both sexes [77]. Moreover, gonadectomy reduced and enhanced platelet aggregability in male and female rats, respectively, whereas treatment with testosterone increased and treatment with estradiol decreased platelet aggregability in both male and female gonadectomized rats, with flutamide and estradiol antagonizing testosterone-enhanced platelet aggregability in male gonadectomized rats [78].

This evidence collected in animal models suggests that estrogens reduce platelet response in both males and females, thus displaying a protective effect against thrombosis, whereas androgens enhance platelet response and ultimately thrombosis-related mortality, finally suggesting that males are more susceptible to thromboembolism compared to females. This evidence seems to be generally confirmed in humans, with the exception of specific conditions.

In humans, the risk of thromboembolism is reported to be at least 3-fold higher in men than in women at any age, with a higher frequency in men during elderly age and a lower frequency in women during fertile age [74, 79-81], suggesting also in humans a possible positive role of estrogens and a negative role of androgens on hemostasis, at least in standard conditions of exposure to normal levels of sex hormones. Noteworthy, in women, conditions of exposure to supraphysiological estrogen levels, such as during the use of estrogen-containing oral contraceptives, or extremely high estrogen levels, such as in pregnancy, represent two exceptions, given that these conditions increase the procoagulant factors FVII, FIX, FX, FXII, and FXIII levels and decrease the anticoagulant factors protein $S$ and antithrombin levels, thus altering the hemostatic balance towards a prothrombotic state $[82,83]$. Interestingly, in transgender women the use of estrogens is independently associated with a 3 -fold increase in cardiovascular mortality, as it is known to induce an increase in body and visceral fat as well as weight and triglycerides, to reduce lean mass, and to promote prothrombotic state $[84,85]$. In transgender men the use of androgens does not increase cardiovascular mortality despite its negative impact not only on hematocrit but also on lipid profile [84, 85]. Notably, in men the condition of testosterone defi- 
ciency, such as in hypogonadism, is associated with an increase in procoagulant factors, including FV, FX, and Creactive protein, and a decrease in anticoagulant factors, such as antithrombin III [86]; this evidence suggests that the condition of androgen deficiency further worsens the susceptibility of men for thrombosis, explaining the exaggerated increase in incidence of thrombosis in old compared to young men. On the other hand, in women in condition of estrogen deficiency, such as in menopause, genetic and environmental factors, including inappropriate diet, smoking habit, and reduction in physical exercise can induce changes in vascular endothelium, platelet response, and blood coagulation, promoting thrombosis [87]; the estrogen deficiency likely contributes to explaining the higher incidence of thrombosis observed in old compared with young women [88].

This evidence suggests that men and women differ in their predisposition to thromboembolism, since in men the thrombotic risk is higher compared to women at any age, and even increased in older compared to younger patients. Although testosterone may not exert a direct negative impact on cardiovascular mortality, testosterone deficiency appears to promote thrombosis, thus contributing to an increased mortality risk in men. Conversely, women take advantage of a less frequent occurrence of thromboembolism during fertile age, but conditions of estrogen deficiency or excess increase thrombotic risk and related mortality in women.

Additionally, exogenous systemic GCs may exert influence on thromboembolism, acting on hemostasis directly and indirectly through changes in sex hormones, with a dichotomous response between sexes [89]. In healthy conditions, GC treatment has been shown to increase FVII, FVIII, and FXI procoagulant factors, whereas in conditions of inflammation status GC therapy inhibits von Willebrand factor and fibrinogen, but increases the antifibrinolytic plasminogen activator inhibitor type 1 (PAI-1) levels, contributing to the occurrence of a hypercoagulability state [90], as also reported in patients with endogenous GC excess such as in Cushing's syndrome, which is associated with thrombosis diathesis [91]. In addition, excess of endogenous GC lowers the testosterone to estradiol ratio in men while increasing it in women [91], thus inducing a sex hormone deficiency status in both sexes which contributes to enhancing thrombotic diathesis.

Taken together, these findings suggest that COVID-19, by promoting peculiar endotheliopathy and thromboinflammation, facilitates the occurrence of micro- and macroangiopathy, leading to fatal thromboem- bolism, and exacerbates the greater thromboembolic risk of men compared to women. Indeed, COVID-19 induces a hypercoagulability state which adds up to the different predisposition to thromboembolism between men and women. Although not fully elucidated, the sum of a pathological condition to a physiological predisposition might help explain the greater severity and the worse outcome of COVID-19 in men compared to women.

\section{The Role of Hypogonadism in Men and Women}

An increasing amount of evidence seems to indicate the condition of sex hormone deficiency as a deleterious factor for immune and inflammatory response or thrombosis diathesis and, consequently, as a negative prognostic factor for the severity and outcome of COVID-19. At confirmation of this hypothesis, an association between male hypogonadism and poor outcome of COVID-19 has been reported. Indeed, in 31 male patients with COVID-19 admitted to the respiratory intensive care unit, low total and calculated free testosterone levels were significantly associated with the presence of negative prognostic factors, including increased serum lactate dehydrogenase, ferritin, and procalcitonin as well as increased neutrophil with decreased lymphocyte count, and with increased mortality [92]. Therefore, low testosterone levels have been suggested as predictors of poor clinical outcome and mortality in COVID-19 [92, 93]. Whether male hypogonadism is an associated comorbidity or a consequence of SARS-CoV-2 infection and development of COVID-19 is still unclear. Smell loss reported by COVID-19 patients might result from injury of the olfactory bulbs and impairment of GnRH secretion (a "Kallman-like" condition), suggesting a secondary origin for male hypogonadism in COVID-19. This hypothesis is in line with experimental studies with SARS-CoV, responsible for SARS, demonstrating that the olfactory bulbs may be a primary conduit for virus entry into the brain, followed by transneuronal spread of the virus [94]. Recently, SARS-CoV-2 infection has been found to induce an increase in TNF and IL-1 in olfactory epithelium of COVID-19 patients with anosmia, therefore suggesting an inflammation-mediated damage of the olfactory bulbs, probably responsible for the anosmia associated with COVID-19 [95]. On the other hand, the documented expression of ACE2 on Leydig cells [37], despite the lack of evidence demonstrating TMPRSS2 co-expression [5], but not excluding the possible co-expression of a different virus priming factor, might permit virus-induced damage of testis function, leading to primary hypogonadism. According to this hypothesis, recent findings have found functional hypogonadism with increased luteinizing hormone levels 
in $31 \%$ and a clear primary hypogonadism in $17 \%$ of male COVID-19 patients admitted to intensive care units [96]. Conversely, the role of the "physiological hypogonadism" seen in menopausal women is yet to be clarified. Interestingly, luteinizing hormone levels are within normal range, but follicle-stimulating hormone levels were reduced in 10 middle-aged to elderly women with COVID-19 [96], likely suggesting the occurrence of secondary hypogonadism. Interestingly, aging is characterized by a physiological sex hormone decline, which is progressive in men during life and sharp in women with the transition from reproductive age to menopause. Such physiological hypogonadism could play a direct or indirect role in the development of systemic inflammation, endotheliopathy, and thromboembolism in COVID-19 patients. Indeed, in men aging is accompanied by a physiological decline in androgen levels [97], or frequently a pathological condition of a real hypogonadism, denominated late-onset hypogonadism [98], which contributes to the progressive increase in the risk of cardiometabolic disease, cardiovascular events, and cardiovascular mortality [99]. Similarly, in women aging is accompanied by a physiological decline in estrogen levels leading to menopause, which contributes to the progressive deterioration of cardiovascular risk factors and increased risk of cardiovascular disease and mortality [100]. Indeed, sex hormones are known to directly impact cardiovascular health. Particularly, androgen decline may predispose to endotheliopathy and thrombosis [101]. Indeed, testosterone is known to modulate the expression of thromboxane A2 receptors in platelets, thus influencing platelet activation, aggregation, and reactivity, and to enhance the synthesis and secretion of endothelial nitric oxide which acts as an inhibitor of platelet activation [101]. On the other side, estrogen decline exerts a negative impact on endothelial function and contributes to the development of thrombotic diathesis, because the sudden reduction in estrogen levels increases oxidative stress through downregulation of the expression of genes related to antioxidants [102], reduction of nitric oxide and increase of reactive oxygen species [103], together with enhancement of the cellular endothelin-1 system and a negative impact on RAS pathway activity [104]. This evidence may partly explain the high mortality rate seen in elderly patients with COVID-19.

\section{COVID-19 in the Elderly: The Role of Inflammaging}

Based on current available evidence, epidemiological data collected in the elderly might reflect the effects of an age-dependent physiological fall in sex hormones in both

Sex Disparities in COVID-19 Severity and Outcome sexes. Moreover, not only sex-biased, but also age-biased immune and inflammatory response and thrombotic diathesis have been reported in the general population and in patients with COVID-19. Global data provide unquestionable evidence that elderly subjects, especially those with preexisting comorbidities, are at higher risk of developing severe disease with poor outcome of COVID-19 [2]. In healthy elderly individuals, the composition and quality of immune response is profoundly reduced by aging because of a physiological reduction in $\mathrm{B}$ cell number and activity, CD8+ T cell and CD4+ T cell activity, and ability to respond to antigens [105]. Aging is also characterized by chronic low-grade inflammation not caused by a pathogen, designated as inflammaging $[102,106]$, which predisposes to higher frailty and earlier mortality and may therefore be responsible for the higher susceptibility to SARS-CoV-2 infection and for the greater severity and worse outcome of COVID-19. Healthy individuals older than 60 years exhibit high baseline serum concentrations of IL-6, IL-8, and C-reactive protein together with increased reactive oxygen species levels [106]. Inflammaging appears to promote the accumulation of senescent cells in the respiratory tract, thus initiating an inflammatory cascade that could inhibit $\mathrm{T}$ cell responses to virusinfected cells [106]. In elderly COVID-19 patients, the defective immune response and the increased proinflammatory IL-6 concentration can promote lung inflammation and injury [107] and foster virus replication [108]. Indeed, innate immune response is also reduced in elderly COVID-19 patients, as demonstrated by the decreased activity of neutrophils, monocytes, and macrophages leading to limited phagocytosis, reduced nitric oxide and superoxide production, and lower migration to infected tissues [109]. Considering the elevated basal inflammatory state in the elderly, SARS-CoV-2 infection has been recently hypothesized to induce a particularly robust and dramatic inflammatory cytokine and chemokine expression responsible for an exaggerated and dysregulated host inflammatory response [109]. Moreover, although high titers of neutralizing and antigen-binding antibodies have been found in elderly COVID-19 patients, it is still unknown whether such antibody response is protective, pathogenic, or the expression of severe disease [109]. Furthermore, the increased oxidative stress of the elderly may contribute to endotheliopathy and potentially to thromboembolism. Noteworthy, the increased risk of thromboembolism reportedly seen in elderly men compared to elderly women might mirror the effects of the physiological decline in testosterone, typically experienced with aging, which can even worsen, more than es- 
tradiol decline in women, this immune defective, proinflammatory, and prothrombotic state [103]. This evidence seems to explain the vulnerability of elderly people, particularly elderly men more than elderly women, to COVID-19.

In Italy, in the update on March 30, 2020 the NIH reported in patients aged $>60$ years an overall higher lethality rate (18.4\%) compared to younger patients (1.1\%). Particularly, in the elderly, the infection rate was higher in men $(21,980,65.2 \%)$ compared to women $(11,726,34.8 \%)$, and the lethality rate in men $(3,520,16 \%)$ was almost double that recorded in women $(1,090,9.3 \%)$. Interestingly, in the latest update on October 14, 2020 the NIH reported in the same age groups a similar trend in the overall lethality rate, which was higher in patients aged $>60$ years $(8.3 \%)$ compared to younger patients $(0.4 \%)$, although the infection rate was $47 \%$ in men and $53 \%$ in women, becoming more similar between sexes, and the lethality rate was $12.9 \%$ in men and $10.1 \%$ in women, with a persistent but slightly higher rate in men compared to women.

Altogether these findings suggest that elderly men might be more susceptible to severe COVID-19 because of a greater predisposition to infections, a weaker immune defense, and an enhanced thrombotic state.

Interestingly, the age-related changes in GCs could either increase vulnerability to infections [110] and prime the response of the immune system [111]. On the other hand, the severe inflammatory responses induced by SARS-CoV-2 provided the basis to suggest, especially in elderly, the use of anti-inflammatory therapy with exogenous systemic corticosteroids to prevent further injury in patients with COVID-19, although the use of such drugs is still debated as they may delay virus elimination and increase the risk of secondary infection, especially in patients with preexisting deterioration of the immune system [112].

\section{Concluding Remarks}

The impact of sex on SARS-CoV-2 infection as well as the severity and outcome of COVID-19 is nowadays an established evidence. Men and women differ in COVID-19 clinical severity and outcome, as suggested by several pieces of evidence. Social habits and comorbidities differ between the two sexes since hygiene practices are more frequently adopted by women than men, whereas smoking and comorbidities are more prevalent in men than women. Virus entry is facilitated in men, who display a genetically based higher lung expression of ACE2 and a testosterone- enhanced TMPRSS2 expression than women, whereas estradiol increases ACE2 activity in women, thus contributing in protecting women from cardiovascular deterioration. Similarly, men display a genetically based higher predisposition to infections than women, who in turn take advantage of a more effective immune system regulation compared to men. Moreover, the direct proinflammatory effects of testosterone and the anti-inflammatory effects of estradiol lead to an enhanced inflammatory system response in men compared to women. Finally, although men and women do not display any difference in genetic predisposition to thromboembolism, men at any age have a higher thrombotic risk than women, in whom the thrombotic risk is lower at fertile age and increases at menopause and/ or under estrogen therapy. In elderly patients inflammaging leads to an immune defective, proinflammatory, and prothrombotic state, which even worsens, in men more than in women, the course of COVID-19.

However, some limitations should be considered. Coexpression of ACE2 and TMPRSS2 on all tissues acting as potential conduits for viral entry is yet to be completely elucidated. While differential effects of testosterone and estradiol on the RAS system have been clearly documented, less is known about the consequences of androgen or estrogen deficiency in both sexes. Particularly, men are known to display a greater cardiovascular risk compared to women. However, while the protective effect of endogenous estrogen in eugonadic women is well documented, scant evidence is available about the mechanisms underlying the greater predisposition of men to cardiovascular events and thromboembolism at any age, independently on gonadic state. Lastly, whether sex hormones differently impact immune, inflammatory, and thrombotic state and whether the differential decline in sex hormones in both sexes influences the clinical severity and final outcome of COVID-19 is not fully understood. Therefore, sex disparities could assist in interpreting epidemiological findings as they contribute to the increased mortality observed worldwide in men in comparison to women. Figure 3 summarizes the sex differences in susceptibility to SARS-CoV-2 infection and sex hormone influences on innate and adaptive immune response, inflammation, and coagulation state.

\section{Perspectives}

Given that currently no specific medical treatment has been demonstrated to be effective in patients with COVID-19, the potential use of hormonal treatment alone or 


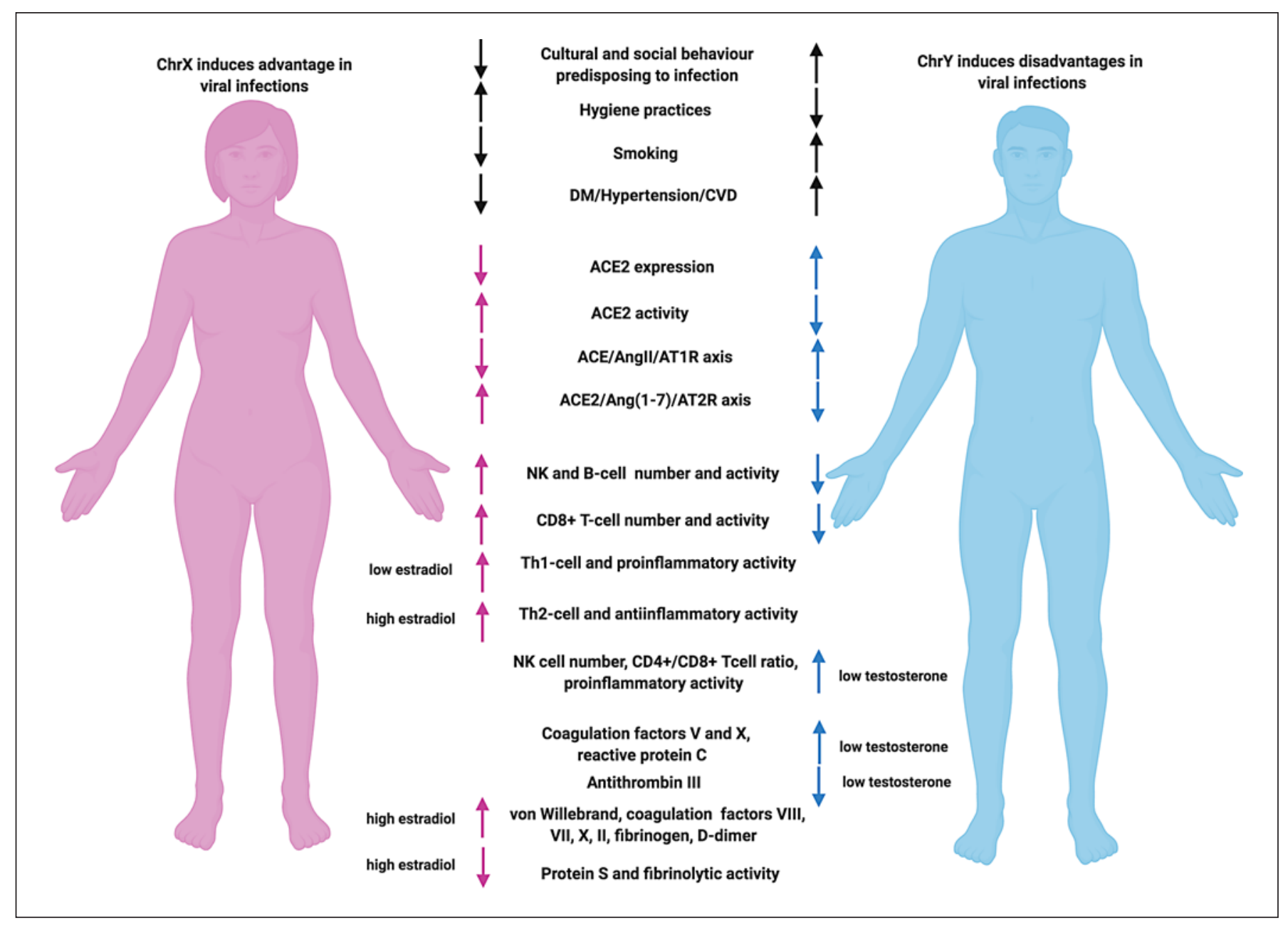

Fig. 3. Sex differences in susceptibility to SARS-CoV-2 infection and sex hormone influence on innate and adaptive immune response, inflammation, and coagulatory state. Figure created with www.biorender.com. ACE, angiotensin-converting enzyme; ACE2, angiotensin-converting enzyme 2; Ang(1-7), angiotensin 1-7; AngII, angiotensin II; ChrX, chromosome X; ChrY, chromosome Y; CVD, cardiovascular disease; DM, diabetes mellitus; $\mathrm{NK}$, natural killer; SARS-CoV-2, severe acute respiratory syndrome coronavirus 2.

in conjunction with proposed therapeutics should receive serious consideration in COVID-19 treatment. According to the hypothesis of a negative role of androgens on the severity and outcome of COVID-19, the employment of anti-androgens has been proposed. Indeed, inhibition of androgens might potentially antagonize TMPRSS2 actions, thus limiting virus internalization into the cells and consequent diffusion in the body [113]. Moreover, spironolactone, a mineralocorticoid receptor blocker with anti-androgenic properties, has been proposed to provide therapeutic benefit in COVID-19 patients by inhibiting the androgen-dependent expression of TMPRSS2, thus preventing SARS-CoV-2 infection $[114,115]$. Notewor- thy, considering the opposite evidence of hypogonadism as a negative factor for the development of a severe COVID-19 with poor outcome, a paradoxical potential beneficial effect of androgen replacement therapy cannot be excluded in patients with clear hypogonadism [99]. On the other hand, according to the evidence of a positive role of estrogens in the development of severe COVID-19 with poor outcome, estrogen treatment has been proposed since it might notably impact the balance between immune and inflammatory responses to SARS-CoV-2, also affecting the occurrence of thrombotic diathesis, therefore influencing mortality. Particularly, low-dose natural estrogens, like isoflavones from soya, given as a 
local nasal spray could directly activate the local nasal immune system by increasing the activity of phagocytes, dendritic cells, and NK cells, thus destroying the virus and preventing its diffusion into the lower respiratory tract or reducing its virulence, as already demonstrated in animal studies [116]. In a randomized clinical trial a tripartite combination with estradiol, the flavonoid quercetin, and vitamin $\mathrm{D}$, known to affect the expression of the majority of human genes encoding SARS-CoV-2 targets, has been proposed as a potential therapeutic intervention to treat and prevent COVID-19 [117]. The hormonally induced reduction of inflammatory response to COVID-19 by selective estrogen receptor modulators might represent another potential therapeutic target in such patients, as selective estrogen receptor modulators are able to suppress the activity of proinflammatory cytokines and induce anti-inflammatory cytokine expression, as previously demonstrated in Ebola patients [118]. Added to antiviral treatment and introduced to a support care protocol immediately on SARS-CoV-2 confirmation, hormonal therapy might contribute to reducing patient hospitalization, with a potential beneficial impact on recovery and reduced mortality rate of patients with COVID-19. Additional hormonal treatments, mainly systemic corticosteroids, might help in reducing inflammation and lung fibrosis and might be useful to counterbalance the corticosteroid insufficiency typically seen in critical illness [119]. On the other hand, the use of systemic corticosteroids might be affected by the occurrence of adverse effects, mainly including suppression of immune response, promotion of thrombosis, and delayed viral clearance, together with cardiometabolic and neuropsychiatric complications [112]. Therefore, a WHO guideline has recommended the use of systemic corticosteroids only for the treatment of severe and critically ill COVID-19 patients, as systemic corticosteroids have been reported to reduce the risk of 28 -day mortality of 8.7 and $6.7 \%$ in patients with COVID-19 who are critically or severely ill, respectively, whereas they may even increase the risk of 28-day mortality in patients with nonsevere COVID-19 [120]. However, at present the efficacy and safety of corticosteroids in COVID-19 need to be further elucidated [120].

In light of these considerations, use of hormonal treatment might offer new therapeutic strategies for COVID-19 alone or in combination with other therapies.

\section{Conflict of Interest Statement}

The authors have no conflicts of interest to declare.

\section{Funding Sources}

None.

\section{Author Contributions}

R. Pivonello conceived the study and supervised the manuscript drafting. R.S. Auriemma and C. Pivonello performed the literature search, contributed to the interpretation of the data, and prepared the figures. R. Pivonello, R.S. Auriemma, and C. Pivonello wrote the manuscript. A.M. Isidori, G. Corona, A. Colao, and R.P. Millar provided significant expert contribution in the scientific content revision process. R.P. Millar critically reviewed the manuscript and revised it for important intellectual content. All authors read and approved the final manuscript.

\section{References}

1 Wiersinga WJ, Rhodes A, Cheng AC, Peacock SJ, Prescott HC. Pathophysiology, Transmission, Diagnosis, and Treatment of Coronavirus Disease 2019 (COVID-19): A Review. JAMA. 2020 Aug;324(8):782-93.

2 Zhou F, Yu T, Du R, Fan G, Liu Y, Liu Z, et al. Clinical course and risk factors for mortality of adult inpatients with COVID-19 in Wuhan, China: a retrospective cohort study. Lancet. 2020 Mar;395(10229):1054-62.

$3 \mathrm{Hu}$ B, Guo H, Zhou P, Shi ZL. Characteristics of SARS-CoV-2 and COVID-19. Nat Rev Microbiol. 2020 doi: 10.1038/s41579-02000459-7 [Epub ahead of print].

4 Hoffmann M, Kleine-Weber H, Schroeder S, Krüger N, Herrler T, Erichsen S, et al. SARSCoV-2 Cell Entry Depends on ACE2 and TMPRSS2 and Is Blocked by a Clinically
Proven Protease Inhibitor. Cell. 2020 Apr; 181(2):271-280.e8.

5 Sungnak W, Huang N, Bécavin C, Berg M, Queen R, Litvinukova M, et al.; HCA Lung Biological Network. SARS-CoV-2 entry factors are highly expressed in nasal epithelial cells together with innate immune genes. Nat Med. 2020 May;26(5):681-7.

6 García LF; Immune Response, Inflammation, and the Clinical Spectrum of COVID-19. Immune Response, Inflammation, and the Clinical Spectrum of COVID-19. Front Immunol. 2020 Jun;11:1441.

7 Ackermann M, Verleden SE, Kuehnel M, Haverich A, Welte T, Laenger F, et al. Pulmonary Vascular Endothelialitis, Thrombosis, and Angiogenesis in Covid-19. N Engl J Med. 2020 Jul;383(2):120-8.
8 Zhang H, Rostami MR, Leopold PL, Mezey JG, O'Beirne SL, Strulovici-Barel Y, et al. Expression of the SARS-CoV-2 ACE2 Receptor in the Human Airway Epithelium. Am J Respir Crit Care Med. 2020 Jul;202(2):219-29.

9 Tay MZ, Poh CM, Rénia L, MacAry PA, Ng LF. The trinity of COVID-19: immunity, inflammation and intervention. Nat Rev Immunol. 2020 Jun;20(6):363-74.

10 Teuwen LA, Geldhof V, Pasut A, Carmeliet P. COVID-19: the vasculature unleashed. Nat Rev Immunol. 2020 Jul;20(7):389-91.

11 Jose RJ, Manuel A. COVID-19 cytokine storm: the interplay between inflammation and coagulation. Lancet Respir Med. 2020 Jun;8(6):e46-7.

12 Connors JM, Levy JH. COVID-19 and its implications for thrombosis and anticoagulation. Blood. 2020 Jun;135(23):2033-40. 
13 La Vignera S, Cannarella R, Condorelli RA, Torre F, Aversa A, Calogero AE. Sex-Specific SARS-CoV-2 Mortality: Among HormoneModulated ACE2 Expression, Risk of Venous Thromboembolism and Hypovitaminosis D. Int J Mol Sci. 2020 Apr;21(8):E2948.

14 Jin JM, Bai P, He W, Wu F, Liu XF, Han DM, et al. Gender Differences in Patients With COVID-19: Focus on Severity and Mortality. Front Public Health. 2020 Apr;8:152.

15 Yu C, Lei Q, Li W, Wang X, Liu W, Fan X, et al. Clinical Characteristics, Associated Factors, and Predicting COVID-19 Mortality Risk: A Retrospective Study in Wuhan, China. Am J Prev Med. 2020 Aug;59(2):168-75.

16 Mikami T, Miyashita H, Yamada T, Harrington $\mathrm{M}$, Steinberg $\mathrm{D}$, Dunn $\mathrm{A}$, et al. Risk Factors for Mortality in Patients with COVID-19 in New York City. J Gen Intern Med. 2020 doi: $10.1007 /$ s11606-020-05983-z [Epub ahead of print].

17 Asfahan S, Deokar K, Dutt N, Niwas R, Jain P, Agarwal M. Extrapolation of mortality in COVID-19: exploring the role of age, sex, comorbidities and health-care related occupation. Monaldi Arch Chest Dis. 2020 May; 90(2).

18 Rivera-Izquierdo M, Del Carmen ValeroUbierna M, R-delAmo JL, Fernández-García MÁ, Martínez-Diz S, Tahery-Mahmoud A, et al. Sociodemographic, clinical and laboratory factors on admission associated with COVID-19 mortality in hospitalized patients: A retrospective observational study. PLoS One. 2020 Jun;15(6):e0235107.

19 Qin L, Li X, Shi J, Yu M, Wang K, Tao Y, et al. Gendered effects on inflammation reaction and outcome of COVID-19 patients in Wuhan. J Med Virol. 2020 Nov;92(11):2684-92.

20 Shah P, Owens J, Franklin J, Mehta A, Heymann W, Sewell W, et al. Demographics, comorbidities and outcomes in hospitalized Covid-19 patients in rural southwest Georgia Ann Med. 2020 Nov;52(7):354-60.

21 Du RH, Liang LR, Yang CQ, Wang W, Cao TZ, Li M, et al. Predictors of mortality for patients with COVID-19 pneumonia caused by SARS-CoV-2: a prospective cohort study. Eur Respir J. 2020 May;55(5):2000524.

22 Posch M, Bauer P, Posch A, König F. Analysis of Austrian COVID-19 deaths by age and sex. Wien Klin Wochenschr. 2020 Nov;132(2122):685-9.

23 COVIDSurg Collaborative. Mortality and pulmonary complications in patients undergoing surgery with perioperative SARSCoV-2 infection: an international cohort study. Lancet. 2020 Jul;396(10243):27-38.

24 Mani VR, Kalabin A, Valdivieso SC, MurrayRamcharan M, Donaldson B. New York Inner City Hospital COVID-19 Experience and Current Data: Retrospective Analysis at the Epicenter of the American Coronavirus Outbreak. J Med Internet Res. 2020 Sep; 22(9):e20548
25 Santorelli G, Sheldon T, West J, Cartwright C, Wright J. COVID-19 in-patient hospital mortality by ethnicity. Wellcome Open Res. 2020 May; $5: 86$.

26 Nikpouraghdam M, Jalali Farahani A, Alishiri G, Heydari S, Ebrahimnia M, Samadinia H, et al. Epidemiological characteristics of coronavirus disease 2019 (COVID-19) patients in Iran: a single center study. J Clin Virol. 2020 Jun; 127:104378.

27 Pan F, Yang L, Li Y, Liang B, Li L, Ye T, et al. Factors associated with death outcome in patients with severe coronavirus disease-19 (COVID-19): a case-control study. Int J Med Sci. 2020 May;17(9):1281-92.

28 Borobia AM, Carcas AJ, Arnalich F, ÁlvarezSala R, Monserrat-Villatoro J, Quintana M, et al.; on behalf of the Covid Hulp Working Group. A Cohort of Patients with COVID-19 in a Major Teaching Hospital in Europe. J Clin Med. 2020 Jun;9(6):E1733.

29 Wu Y, Guo W, Liu H, Qi B, Liang K, Xu H, et al. Clinical outcomes of 402 patients with COVID-2019 from a single center in Wuhan, China. J Med Virol. 2020 Nov;92(11):2751-7.

30 Deiana G, Azara A, Dettori M, Delogu F, Vargiu G, Gessa I, et al. Deaths in SARS-Cov-2 Positive Patients in Italy: The Influence of Underlying Health Conditions on Lethality. Int J Environ Res Public Health. 2020 Jun; 17(12):E4450

31 Channappanavar R, Fett C, Mack M, Ten Eyck PP, Meyerholz DK, Perlman S. SexBased Differences in Susceptibility to Severe Acute Respiratory Syndrome Coronavirus Infection. J Immunol. 2017 May; 198(10): 4046-53.

32 Wenham C, Smith J, Morgan R; Gender and COVID-19 Working Group. COVID-19: the gendered impacts of the outbreak. Lancet. 2020 Mar;395(10227):846-8

33 The Lancet. The gendered dimensions of COVID-19. Lancet. 2020 Apr;395(10231): 1168.

34 Anderson JL, Warren CA, Perez E, Louis RI, Phillips S, Wheeler J, et al. Gender and ethnic differences in hand hygiene practices among college students. Am J Infect Control. 2008 Jun;36(5):361-8.

35 Tukiainen T, Villani AC, Yen A, Rivas MA, Marshall JL, Satija R, et al. Landscape of X chromosome inactivation across human tissues. Nature. 2017 Oct;550(7675):244-8.

36 Corley MJ, Ndhlovu LC. DNA methylation analysis of the COVID-19 host cell receptor, angiotensin I converting enzyme 2 gene (ACE2) in the respiratory system reveal age and gender differences. Preprints. 2020 doi: 10.20944/preprints202003.0295.v1] [Preprint].

37 Wang Z, Xu X. scRNA-seq Profiling of Human Testes Reveals the Presence of the ACE2 Receptor, A Target for SARS-CoV-2 Infection in Spermatogonia, Leydig and Sertoli Cells. Cells. 2020 Apr;9(4):E920.
38 Reis FM, Bouissou DR, Pereira VM, Camargos AF, dos Reis AM, Santos RA. Angiotensin-(1-7), its receptor Mas, and the angiotensin-converting enzyme type 2 are expressed in the human ovary. Fertil Steril. 2011 Jan;95(1): 176-81.

39 Corona G, Baldi E, Isidori AM, Paoli D, Pallotti F, De Santis L, et al. SARS-CoV-2 infection, male fertility and sperm cryopreservation: a position statement of the Italian Society of Andrology and Sexual Medicine (SIAMS) (Società Italiana di Andrologia e Medicina della Sessualità). J Endocrinol Invest. 2020 Aug;43(8):1153-7.

40 Asselta R, Paraboschi EM, Mantovani A, Duga S. ACE2 and TMPRSS2 variants and expression as candidates to sex and country differences in COVID-19 severity in Italy. Aging (Albany NY). 2020 Jun;12(11):10087-98.

41 Wang S, Zhou X, Zhang T, Wang Z. The need for urogenital tract monitoring in COVID-19. Nat Rev Urol. 2020 Jun;17(6):314-5.

42 Goad J, Rudolph J, Rajkovic A. Female reproductive tract has low concentration of SARSCoV2 receptors. bioRxiv. 2020 doi: 10.1101/2020.06.20.163097 [Preprint].

43 Liu J, Ji H, Zheng W, Wu X, Zhu JJ, Arnold $\mathrm{AP}$, et al. Sex differences in renal angiotensin converting enzyme 2 (ACE2) activity are $17 \beta$-oestradiol-dependent and sex chromosome-independent. Biol Sex Differ. 2010 Nov; 1(1):6.

44 Chen YF, Naftilan AJ, Oparil S. Androgendependent angiotensinogen and renin messenger RNA expression in hypertensive rats. Hypertension. 1992 May;19(5):456-63.

45 Ellison KE, Ingelfinger JR, Pivor M, Dzau VJ. Androgen regulation of rat renal angiotensinogen messenger RNA expression. J Clin Invest. 1989 Jun;83(6):1941-5.

46 Mishra JS, Hankins GD, Kumar S. Testosterone downregulates angiotensin II type-2 receptor via androgen receptor-mediated ERK1/2 MAP kinase pathway in rat aorta. J Renin Angiotensin Aldosterone Syst. 2016 Oct;17(4):1470320316674875.

47 Dalpiaz PL, Lamas AZ, Caliman IF, Ribeiro RF Jr, Abreu GR, Moyses MR, et al.; Sex Hormones Promote Opposite Effects on ACE and ACE2 Activity, Hypertrophy and Cardiac Contractility in Spontaneously Hypertensive Rats. Sex Hormones Promote Opposite Effects on ACE and ACE2 Activity, Hypertrophy and Cardiac Contractility in Spontaneously Hypertensive Rats. PLoS One. 2015 May;10(5):e0127515.

48 Baratchian M, McManus JM, Berk M, Nakamura F, Mukhopadhyay S, Xu W, et al. Sex, androgens and regulation of pulmonary AR, TMPRSS2 and ACE2. bioRxiv. 2020 doi: 10.1101/2020.04.21.051201 [Preprint].

49 Milsted A, Underwood AC, Dunmire J, DelPuerto HL, Martins AS, Ely DL, et al. Regulation of multiple renin-angiotensin system genes by Sry. J Hypertens. 2010 Jan;28(1):5964. 
50 Bukowska A, Spiller L, Wolke C, Lendeckel U, Weinert S, Hoffmann J, et al. Protective regulation of the ACE2/ACE gene expression by estrogen in human atrial tissue from elderly men. Exp Biol Med (Maywood). 2017 Aug; 242(14):1412-23.

51 Hilliard LM, Sampson AK, Brown RD, Denton KM. The "his and hers" of the renin-angiotensin system. Curr Hypertens Rep. 2013 Feb;15(1):71-9.

52 Shoemaker R, Tannock LR, Su W, Gong M, Gurley SB, Thatcher SE, et al. Adipocyte deficiency of ACE2 increases systolic blood pressures of obese female C57BL/6 mice. Biol Sex Differ. 2019 Sep;10(1):45.

53 Lin B, Ferguson C, White JT, Wang S, Vessella $\mathrm{R}$, True LD, et al. Prostate-localized and androgen-regulated expression of the membrane-bound serine protease TMPRSS2. Cancer Res. 1999 Sep;59(17):4180-4.

54 Setlur SR, Mertz KD, Hoshida Y, Demichelis F, Lupien M, Perner S, et al. Estrogen-dependent signaling in a molecularly distinct subclass of aggressive prostate cancer. J Natl Cancer Inst. 2008 Jun;100(11):815-25.

55 Foulds CE, Tsimelzon A, Long W, Le A, Tsai SY, Tsai MJ, et al. Research resource: expression profiling reveals unexpected targets and functions of the human steroid receptor RNA activator (SRA) gene. Mol Endocrinol. 2010 May;24(5):1090-105.

56 Remy KE, Mazer M, Striker DA, Ellebedy AH, Walton AH, Unsinger J, et al. Severe immunosuppression and not a cytokine storm characterizes COVID-19 infections. JCI Insight. 2020 Sep;5(17):140329.

57 Klein SL, Flanagan KL. Sex differences in immune responses. Nat Rev Immunol. 2016 Oct; 16(10):626-38.

58 Libert C, Dejager L, Pinheiro I. The X chromosome in immune functions: when a chromosome makes the difference. Nat Rev Immunol. 2010 Aug;10(8):594-604.

59 Maan AA, Eales J, Akbarov A, Rowland J, Xu $\mathrm{X}$, Jobling $\mathrm{MA}$, et al. The $\mathrm{Y}$ chromosome: a blueprint for men's health? Eur J Hum Genet. 2017 Nov;25(11):1181-8.

60 Krementsov DN, Case LK, Dienz O, Raza A, Fang Q, Ather JL, et al. Genetic variation in chromosome $\mathrm{Y}$ regulates susceptibility to influenza A virus infection. Proc Natl Acad Sci USA. 2017 Mar;114(13):3491-6.

61 Chamekh M, Deny M, Romano M, Lefèvre N, Corazza F, Duchateau J, et al. Differential Susceptibility to Infectious Respiratory Diseases between Males and Females Linked to SexSpecific Innate Immune Inflammatory Response. Front Immunol. 2017 Dec;8:1806.

62 Souyris M, Cenac C, Azar P, Daviaud D, Canivet A, Grunenwald S, et al. TLR7 escapes X chromosome inactivation in immune cells. Sci Immunol. 2018 Jan;3(19):eaap8855.

63 Bereshchenko O, Bruscoli S, Riccardi C. Glucocorticoids, Sex Hormones, and Immunity. Front Immunol. 2018 Jun;9:1332.
64 Chrousos GP. Stress and sex versus immunity and inflammation. Sci Signal. 2010 Oct; 3(143):pe36.

65 Giannis D, Ziogas IA, Gianni P. Coagulation disorders in coronavirus infected patients: COVID-19, SARS-CoV-1, MERS-CoV and lessons from the past. J Clin Virol. 2020 Jun; 127:104362.

66 Franchini M, Marano G, Cruciani M, Mengoli C, Pati I, Masiello F, et al. COVID-19-associated coagulopathy. Diagnosis (Berl). 2020 Nov;7(4):357-63.

67 Páramo JA. Pulmonary embolism, pulmonary microvascular thrombosis, or both in COVID-19? Clin Appl Thromb Hemost. 2020 Jan-Dec;26:1076029620933953.

68 Jackson SP, Darbousset R, Schoenwaelder SM. Thromboinflammation: challenges of therapeutically targeting coagulation and other host defense mechanisms. Blood. 2019 Feb;133(9):906-18.

69 Ranucci M, Ballotta A, Di Dedda U, Bayshnikova E, Dei Poli M, Resta M, et al. The procoagulant pattern of patients with COVID-19 acute respiratory distress syndrome. J Thromb Haemost. 2020 Jul;18(7):1747-51.

70 Edler C, Schröder AS, Aepfelbacher M, Fitzek A, Heinemann A, Heinrich F, et al. Dying with SARS-CoV-2 infection - an autopsy study of the first consecutive 80 cases in Hamburg, Germany. Int J Legal Med. 2020 Jul; 134(4):1275-84.

71 Beyrouti R, Adams ME, Benjamin L, Cohen H, Farmer SF, Goh YY, et al. Characteristics of ischaemic stroke associated with COVID-19. J Neurol Neurosurg Psychiatry. 2020 Aug;91(8):889-91.

72 Lodigiani C, Iapichino G, Carenzo L, Cecconi M, Ferrazzi P, Sebastian T, et al.; Humanitas COVID-19 Task Force. Venous and arterial thromboembolic complications in COVID-19 patients admitted to an academic hospital in Milan, Italy. Thromb Res. 2020 Jul; 191:9-14.

73 Roach RE, Cannegieter SC, Lijfering WM. Differential risks in men and women for first and recurrent venous thrombosis: the role of genes and environment. J Thromb Haemost. 2014 Oct;12(10):1593-600.

74 Salzano A, Demelo-Rodriguez P, Marra AM, Proietti M. A Focused Review of Gender Differences in Antithrombotic Therapy. Curr Med Chem. 2017;24(24):2576-88.

75 Emms H, Lewis GP. Sex and hormonal influences on platelet sensitivity and coagulation in the rat. Br J Pharmacol. 1985 Nov;86(3): 557-63.

76 Emms H, Lewis GP. The effect of synthetic ovarian hormones on an in vivo model of thrombosis in the rat. Br J Pharmacol. 1985 Jan;84(1):243-8.

77 Uzunova A, Ramey E, Ramwell PW. Effect of testosterone, sex and age on experimentally induced arterial thrombosis. Nature. 1976 Jun;261(5562):712-3.
78 Johnson M, Ramey E, Ramwell PW. Androgen-mediated sensitivity in platelet aggregation. Am J Physiol. 1977 Apr;232(4):H381-5.

79 Kyrle PA, Minar E, Bialonczyk C, Hirschl M, Weltermann A, Eichinger S. The risk of recurrent venous thromboembolism in men and women. N Engl J Med. 2004 Jun;350(25): 2558-63.

80 Naess IA, Christiansen SC, Romundstad P, Cannegieter SC, Rosendaal FR, Hammerstrøm J. Incidence and mortality of venous thrombosis: a population-based study. J Thromb Haemost. 2007 Apr;5(4):692-9.

81 Roy-O’Reilly M, McCullough LD. Sex differences in stroke: the contribution of coagulation. Exp Neurol. 2014 Sep;259:16-27.

82 Hvas AM, Favaloro EJ. Gender related issues in thrombosis and hemostasis. Expert Rev Hematol. 2017 Nov;10(11):941-9.

83 Rosendaal FR, Van Hylckama Vlieg A, Tanis BC, Helmerhorst FM. Estrogens, progestogens and thrombosis. J Thromb Haemost. 2003 Jul;1(7):1371-80.

84 Seal LJ. Cardiovascular disease in transgendered people: a review of the literature and discussion of risk. JRSM Cardiovasc Dis. 2019 Sep;8:2048004019880745.

85 Goldstein Z, Khan M, Reisman T, Safer JD. Managing the risk of venous thromboembolism in transgender adults undergoing hormone therapy. J Blood Med. 2019 Jul;10:20916.

86 Erem C, Kocak M, Hacihasanoglu A, Yilmaz M. Blood coagulation and fibrinolysis in male patients with hypogonadotropic hypogonadism: plasma factor $\mathrm{V}$ and factor $\mathrm{X}$ activities increase in hypogonadotropic hypogonadism. J Endocrinol Invest. 2008 Jun;31(6):53741.

87 Renda G, Patti G, Lang IM, Siller-Matula JM, Hylek EM, Ambrosio G, et al.; Working Group on Thrombosis of the Italian Society of Cardiology. Thrombotic and hemorrhagic burden in women: gender-related issues in the response to antithrombotic therapies. Int J Cardiol. 2019 Jul;286:198-207.

88 Previtali E, Bucciarelli P, Passamonti SM, Martinelli I. Risk factors for venous and arterial thrombosis. Blood Transfus. 2011 Apr; 9(2):120-38.

89 Isidori AM, Minnetti M, Sbardella E, Graziadio C, Grossman AB. Mechanisms in endocrinology: the spectrum of haemostatic abnormalities in glucocorticoid excess and defect. Eur J Endocrinol. 2015 Sep; 173(3):R101-13.

90 van Zaane B, Nur E, Squizzato A, Gerdes VE Büller HR, Dekkers OM, et al. Systematic review on the effect of glucocorticoid use on procoagulant, anti-coagulant and fibrinolytic factors. J Thromb Haemost. 2010 Nov;8(11): 2483-93.

91 Pivonello R, Isidori AM, De Martino MC, Newell-Price J, Biller BM, Colao A. Complications of Cushing's syndrome: state of the art. Lancet Diabetes Endocrinol. 2016 Jul; 4(7):611-29. 
92 Rastrelli G, Di Stasi V, Inglese F, Beccaria M, Garuti M, Di Costanzo D, et al. Low testosterone levels predict clinical adverse outcomes in SARS-CoV-2 pneumonia patients. Andrology. 2020 doi: 10.1111/andr.12821 [Epub ahead of print].

93 Pozzilli P, Lenzi A. Commentary: Testosterone, a key hormone in the context of COVID-19 pandemic. Metabolism. 2020 Jul; 108:154252.

94 Netland J, Meyerholz DK, Moore S, Cassell M, Perlman S. Severe acute respiratory syndrome coronavirus infection causes neuronal death in the absence of encephalitis in mice transgenic for human ACE2. J Virol. 2008 Aug;82(15):7264-75.

95 Torabi A, Mohammadbagheri E, Akbari Dilmaghani N, Bayat AH, Fathi M, Vakili K, et al. Proinflammatory Cytokines in the Olfactory Mucosa Result in COVID-19 Induced Anosmia. ACS Chem Neurosci. 2020 Jul; 11(13):1909-13.

96 Schroeder MT, Jarczak D, Nierhaus A, Bai T, Jacobsen H, Zickler M, et al. The majority of male patients with COVID-19 present low testosterone levels on admission to Intensive Care in Hamburg, Germany: a retrospective cohort study. medRxiv. 2020 doi: 10.1101/2020.05.07.20073817 [Preprint].

97 Kaufman JM, Lapauw B, Mahmoud A, T'Sjoen G, Huhtaniemi IT. Aging and the Male Reproductive System. Endocr Rev. 2019 Aug;40(4):906-72.

98 Corona G, Rastrelli G, Maggi M. Diagnosis and treatment of late-onset hypogonadism: systematic review and meta-analysis of TRT outcomes. Best Pract Res Clin Endocrinol Metab. 2013 Aug;27(4):557-79.

99 Kloner RA, Carson C 3rd, Dobs A, Kopecky S, Mohler ER 3rd. Testosterone and Cardiovascular Disease. J Am Coll Cardiol. 2016 Feb;67(5):545-57.

100 Colpani V, Baena CP, Jaspers L, van Dijk GM, Farajzadegan Z, Dhana K, et al. Lifestyle factors, cardiovascular disease and allcause mortality in middle-aged and elderly women: a systematic review and meta-analysis. Eur J Epidemiol. 2018 Sep;33(9):83145.
101 Giagulli VA, Guastamacchia E, Magrone T, Jirillo E, Lisco G, De Pergola G, et al. Worse progression of COVID-19 in men: is testosterone a key factor? Andrology. 2020 doi: 10.1111/andr.12836 [Epub ahead of print].

102 Vitale G, Salvioli S, Franceschi C. Oxidative stress and the ageing endocrine system. Nat Rev Endocrinol. 2013 Apr;9(4):228-40.

103 Froldi G, Dorigo P. Endothelial dysfunction in Coronavirus disease 2019 (COVID-19): gender and age influences. Med Hypotheses. 2020 Nov; 144:110015.

104 Gohar EY, Pollock DM. Sex-Specific Contributions of Endothelin to Hypertension. Curr Hypertens Rep. 2018 Jun;20(7):58.

105 Montecino-Rodriguez E, Berent-Maoz B, Dorshkind K. Causes, consequences, and reversal of immune system aging. J Clin Invest. 2013 Mar;123(3):958-65.

106 Akbar AN, Gilroy DW. Aging immunity may exacerbate COVID-19. Science. 2020 Jul;369(6501):256-7.

$107 \mathrm{Yu}$ M, Zheng X, Witschi H, Pinkerton KE. The role of interleukin- 6 in pulmonary inflammation and injury induced by exposure to environmental air pollutants. Toxicolog Sci. 2002 Aug;68(2):488-97.

108 Velazquez-Salinas L, Verdugo-Rodriguez A, Rodriguez LL, Borca MV. The Role of Interleukin 6 During Viral Infections. Front Microbiol. 2019 May; 10:1057.

109 Channappanavar R, Perlman S. Age-related susceptibility to coronavirus infections: role of impaired and dysregulated host immunity. J Clin Invest. 2020 Nov; 144115.

110 Hasenmajer V, Sbardella E, Sciarra F, Minnetti M, Isidori AM, Venneri MA. The immune system in Cushing's syndrome. Trends Endocrinol Metab. 2020 Sep;31(9): 655-69.

111 Isidori AM, Arnaldi G, Boscaro M, Falorni A, Giordano C, Giordano R, et al. COVID-19 infection and glucocorticoids: update from the Italian Society of Endocrinology Expert Opinion on steroid replacement in adrenal insufficiency. J Endocrinol Invest. 2020 Aug;43(8):1141-7.
112 Zhang W, Zhao Y, Zhang F, Wang Q, Li T, Liu Z, et al. The use of anti-inflammatory drugs in the treatment of people with severe coronavirus disease 2019 (COVID-19): the Perspectives of clinical immunologists from China. Clin Immunol. 2020 May;214: 108393.

113 De Toni L, Garolla A, Di Nisio A, Rocca MS, Foresta C. Caution in the management of SARS-CoV-2 infection in males. Andrology. 2020 doi: 10.1111/andr.12829 [Epub ahead of print].

114 Cadegiani FA. Can spironolactone be used to prevent COVID-19-induced acute respiratory distress syndrome in patients with hypertension? Am J Physiol Endocrinol Metab. 2020 May;318(5):E587-8.

115 Liaudet L, Szabo C. Blocking mineralocorticoid receptor with spironolactone may have a wide range of therapeutic actions in severe COVID-19 disease. Crit Care. 2020 Jun; 24(1):318

116 Di Stadio A, Della Volpe A, Ralli M, Ricci G. Gender differences in COVID-19 infection. The estrogen effect on upper and lower airways. Can it help to figure out a treatment? Eur Rev Med Pharmacol Sci. 2020 May; 24(10):5195-6.

117 Glinsky GV. Tripartite Combination of Candidate Pandemic Mitigation Agents: Vitamin D, Quercetin, and Estradiol Manifest Properties of Medicinal Agents for Targeted Mitigation of the COVID-19 Pandemic Defined by Genomics-Guided Tracing of SARS-CoV-2 Targets in Human Cells. Biomedicines. 2020 May;8(5):E129.

118 Zhao Y, Ren J, Harlos K, Jones DM, Zeltina A, Bowden TA, et al. Toremifene interacts with and destabilizes the Ebola virus glycoprotein. Nature. 2016 Jul;535(7610):169-72.

119 Isidori AM, Pofi R, Hasenmajer V, Lenzi A, Pivonello R. Use of glucocorticoids in patients with adrenal insufficiency and COVID-19 infection. Lancet Diabetes Endocrinol. 2020 Jun;8(6):472-3.

120 World Health Organization. Corticosteroids for COVID-19. www.who.int/ publications/i/item/WHO-2019-nCoVCorticosteroids-2020.1. 